Wild Plants, Mushrooms and Nuts 


\section{Wild Plants, Mushrooms and Nuts: Functional Food Properties and Applications}

Edited by Isabel C. F. R. Ferreira, Patricia Morales, and Lillian Barros

Mountain Research Centre (CIMO), School of Agriculture, Polytechnic Institute of Bragança, Portugal

Department of Nutrition and Bromatology II, Faculty of Pharmacy,

Complutense University of Madrid, Spain

Mountain Research Centre (CIMO), School of Agriculture, Polytechnic Institute of Bragança, Portugal 
This edition first published 2017

(c) 2017 John Wiley \& Sons, Ltd

\section{Registered Office}

John Wiley \& Sons, Ltd, The Atrium, Southern Gate, Chichester, West Sussex, PO19 8SQ, United Kingdom

For details of our global editorial offices, for customer services and for information about how to apply for permission to reuse the copyright material in this book please see our website at www.wiley.com.

The right of the author to be identified as the author of this work has been asserted in accordance with the Copyright, Designs and Patents Act 1988.

All rights reserved. No part of this publication may be reproduced, stored in a retrieval system, or transmitted, in any form or by any means, electronic, mechanical, photocopying, recording or otherwise, except as permitted by the UK Copyright, Designs and Patents Act 1988, without the prior permission of the publisher.

Wiley also publishes its books in a variety of electronic formats. Some content that appears in print may not be available in electronic books.

Designations used by companies to distinguish their products are often claimed as trademarks. All brand names and product names used in this book are trade names, service marks, trademarks or registered trademarks of their respective owners. The publisher is not associated with any product or vendor mentioned in this book.

Limit of Liability/Disclaimer of Warranty: While the publisher and author have used their best efforts in preparing this book, they make no representations or warranties with respect to the accuracy or completeness of the contents of this book and specifically disclaim any implied warranties of merchantability or fitness for a particular purpose. It is sold on the understanding that the publisher is not engaged in rendering professional services and neither the publisher nor the author shall be liable for damages arising herefrom. If professional advice or other expert assistance is required, the services of a competent professional should be sought.

\section{Library of Congress Cataloging-in-Publication Data}

Names: Ferreira, Isabel C. F. R., 1979- editor. | Barros, Lillian, editor. | Patricia Morales, editor. Title: Wild plants, mushrooms and nuts : functional food properties and applications / [edited by] Isabel Ferreira, Patricia Morales, Lillian Barros

Description: Chichester, UK ; Hoboken, NJ : John Wiley \& Sons, 2017. I Includes bibliographical references and index.

Identifiers: LCCN 2016036173 (print) | LCCN 2016045177 (ebook) | ISBN 9781118944622 (cloth) | ISBN 9781118944639 (pdf) | ISBN 9781118944646 (epub)

Subjects: LCSH: Functional foods. | Mushrooms. | Nuts. | Wild plants, Edible.

Classification: LCC QP144.F85 W54 2016 (print) | LCC QP144.F85 (ebook) | DDC 581.6/32-dc23

LC record available at https://lccn.loc.gov/2016036173

A catalogue record for this book is available from the British Library.

Set in 10/12pt Warnock by SPi Global, Pondicherry, India 


\section{Contents}

List of Contributors $x i$

Preface $x v$

1 Introduction: The Increasing Demand for Functional Foods 1

Natália Martins, Patricia Morales, Lillian Barros, and Isabel C. F. R. Ferreira

1.1 Food Patterns: A Cross-sectional Approach and Brief Overview 1

1.2 Nutrition and Health: Facts and Tendencies 2

1.2.1 Evidence-based Medicine: Past to Present 2

1.2.2 Modern Food Patterns: An (Un)Healthy Yield 3

1.3 Functional Foods Diversity and Related Applications: A World of (Un)Explored Biofunctionalities 4

1.3.1 Food and Dietary Supplements, Botanicals, and Nutraceuticals: Clarifying Misinterpreted Concepts 5

1.4 Functional Foods Versus Bioactive Molecules: Hierarchies and Regulatory Practices 6

1.5 Challenges and Opportunities: A Multidimensional Perspective 8

1.6 Conclusion 9

References 10

2 The Numbers Behind Mushroom Biodiversity 15

Anabela Martins

2.1 Origin and Diversity of Fungi 15

2.2 Ecological Diversity 18

2.2.1 Freshwater Fungi 21

2.2.2 Marine Fungi 21

2.2.3 Endophytes of Plant Leaves and Stems 22

2.2.4 Fungi from Arthropod and Invertebrate Animals 22

2.3 Global Diversity of Soil Fungi 22

2.4 Wild Edible Fungi 24

2.4.1 Diversity of Wild Edible Mushrooms 30

2.4.2 Medicinal Mushrooms 32

2.5 Cultivation of Edible Fungi 38

2.6 Social and Economic Interest in Edible Mushrooms 41

2.7 Edible Mushroom World Production and Commercialization 42

2.8 Conclusion 49

References 50 
The Nutritional Benefits of Mushrooms 65

Carolina Barroetaveña and Carolina V. Toledo

$3.1 \quad$ Introduction 65

3.2 Nutritional Properties of Mushrooms 66

3.2.1 Proteins and Amino Acids 66

3.2.2 Carbohydrates: Available Carbohydrates and Dietary Fiber 69

3.2.3 Lipids 71

3.2.4 Energetic Value/Caloric Content 72

3.2.5 Ash and Mineral Elements 73

3.3 Vitamins 73

3.4 Conclusion 75

References 76

$4 \quad$ The Bioactive Properties of Mushrooms 83

Marina Soković, Ana Ćirić, Jasmina Glamočlija, and Dejan Stojković

4.1 Introduction 83

4.2 Antimicrobial Activity of Edible and Medicinal Fungi 84

4.2.1 Antibacterial Activity of Mushroom Extracts 84

4.2.2 Compounds Isolated from Mushrooms as Bacterial Growth Inhibitors 84

4.2.3 Antifungal Activity of Crude Mushroom Extracts 92

4.2.4 Isolated Compounds from Mushrooms Express Antifungal Potency 93

4.3 Mushrooms as a Reliable Source of Antioxidants for

Disease Prevention 95

4.4 Could Mushrooms Be Used as Cytotoxic and Antitumor Agents? 100

4.4.1 Cytotoxic Features of Wild Mushroom Extracts 100

4.4.2 Mushroom Polysaccharides, $\beta$-, and $\alpha$-Glucans as Antitumor Agents 100

4.4.3 Cytotoxic Potency of Terpenoids and Related Compounds from Mushrooms 104

4.4.4 Mushroom Sterols Inhibit the Growth of Carcinoma Cell Lines 104

4.5 Controlling Obesity, Metabolic Syndrome, and Diabetes Mellitus with Mushrooms 108

4.6 Conclusion 111

References 111

5 The Use of Mushrooms in the Development of Functional Foods, Drugs, and Nutraceuticals 123

Humberto J. Morris, Gabriel Llauradó, Yaixa Beltrán, Yamila Lebeque, Rosa

C. Bermúdez, Nora García, Isabelle Gaime-Perraud, and Serge Moukha

5.1 Introduction 123

5.2 A Window into the "Garden" of a Novel Class of Products 125

5.3 Main Uses of Edible Medicinal Mushrooms in the Age of Human Health Crises 127

5.3.1 Mushrooms as Functional Foods: A Paradigm of Integrating Tradition and Novelty 128

5.3.1.1 Proven Functional Properties 129 
5.3.2 Mushroom Nutraceuticals 135

5.3.3 Mushrooms as a Significant Source of Drugs: Lessons from

Wasser's Discovery Pathway 139

5.4 Conclusion 146

References 149

6 The Consumption of Wild Edible Plants 159

Ana Maria Carvalho and Ana Maria Barata

6.1 Wild Edible Plants 159

6.1.1 Contribution of Wild Edible Plants to People's Diets and

Daily Lives 160

6.1.1.1 Famine Foods 161

6.1.1.2 Weeds 162

6.1.2 New Trends in Edible Wild Plant Consumption 163

6.1.3 Wild Edible Plants, Food Security, and Research Approaches 164

6.2 Foraging and Wild Edible Plant Resources 165

6.2.1 Wild Plant Resources Worldwide 165

6.2.1.1 Africa 166

6.2.1.2 Americas 171

6.2.1.3 Asia 173

6.2.1.4 Europe 174

6.2.1.5 Oceania 175

6.3 Wild Relatives of Crop Plants 177

6.3.1 CWR Inventories and Checklists 179

6.4 Enhancing Biodiversity and Plant Genetic Resources

Conservation 181

6.4.1 Conservation Strategies 181

6.4.2 Promoting and Strengthening Biocultural Heritage 183

6.5 Culturally Significant Wild Edible Plants 185

6.6 Conclusion 187

References 188

7 Wild Greens as Source of Nutritive and Bioactive Compounds Over the World 199

Patricia Morales, Patricia García Herrera, Maria Cruz Matallana González, Montaña Cámara Hurtado, and Maria de Cortes Sánchez Mata

7.1 Introduction 199

7.2 Wild Greens as a Source of Nutritive and Bioactive Compounds in Different Geographical Areas 200

7.2.1 Traditional Wild Greens from Africa 200

7.2.2 Wild Vegetables Consumed in the Americas 213

7.2.3 Asian Wild Edible Greens 222

7.2.4 Vegetables Traditionally Consumed in Europe 226

7.3 Implications of Wild Greens Consumption for Human Health: Safely Gathering Wild Edible Plants 243

7.4 Conclusion 248

References 249 
viii $\mid$ Contents

$8 \quad$ Nutrients and Bioactive Compounds in Wild Fruits Through

Different Continents 263

Virginia Fernández-Ruiz, Patricia Morales, Brígida María Ruiz-Rodríguez, and

Esperanza Torija Isasa

8.1 Introduction 263

8.2 African Wild Fruits as a Source of Nutrients and Bioactive Compounds 264

8.3 American Wild Fruits as a Source of Nutrients and Bioactive Compounds 273

8.4 Asian Wild Fruits as a Source of Nutrients and Bioactive Compounds 287

8.5 European Wild Fruits as a Source of Nutrients and Bioactive Compounds 291

8.6 Conclusion 306

References 306

9 Wild Plant-Based Functional Foods, Drugs, and Nutraceuticals 315 José Pinela, Márcio Carocho, Maria Inês Dias, Cristina Caleja, Lillian Barros, and Isabel C. F. R. Ferreira

9.1 Introduction 315

9.2 Wild Plants and Functional Foods 316

9.2.1 The Concept and Recent Trends in Functional Foods 316

9.2.2 Classification and Development of Functional Foods 318

9.2.3 Wild Plants Used as Functional Foods 319

9.3 Wild Plant-Based Nutraceuticals 326

9.3.1 The Emerging Concept and Applications of Nutraceuticals 326

9.3.2 Recent Advances in Formulations for Nutraceuticals 328

9.3.3 Examples of Nutraceuticals Based on Wild Plants 329

9.4 Wild Plant-Based Drugs 335

9.4.1 From the Bioactive Phytochemical to the Active Principle 335

9.4.2 Common Formulations in Drugs from Plant Origin 337

9.4.3 Wild Plant-Based Drugs for Different Therapeutic Targets 340

9.5 Conclusion 341

References 342

10 Nuts: Agricultural and Economic Importance Worldwide 353

Albino Bento, Paula Cabo, and Ricardo Malheiro

$10.1 \quad$ Introduction 353

10.2 Almond 354

10.2.1 Evolution of Almond Production and Trade Facts 356

10.2.2 Consumption of Almonds Worldwide 357

10.3 Chestnut 359

10.3.1 Evolution of Chestnut Production and Trade Facts 360

10.3.2 Consumption of Chestnuts Worldwide 362

10.4 Hazelnut 362

10.4.1 Evolution of Hazelnut Production and Trade Facts 365

10.4.2 Consumption of Hazelnuts Worldwide 367

10.5 Walnut 367

10.5.1 Evolution of Walnut Production and Trade Facts 369

10.5.2 Consumption of Walnuts Worldwide 374

10.6 Conclusion 374

References 374 
11 Recent Advances in Our Knowledge of the Biological

Properties of Nuts 377

Ryszard Amarowicz, Yi Gong, and Ronald B. Pegg

$11.1 \quad$ Introduction 377

11.2 Nuts as a Source of Nutrients, Phytosterols, and Natural Antioxidants 378

11.2.1 Nuts as a Source of Energy and Macronutrients 378

11.2.2 Biological Value of Nut Proteins 378

11.2.3 Nuts as a Source of Vitamins and Minerals 378

11.2.4 Nuts as a Source of Essential Fatty Acids and Phytosterols 382

11.2.5 Phenolic Compounds Originating from Tree Nuts as Natural Antioxidants 382

11.3 Health Benefits of Nuts 389

11.3.1 Health-Promoting Properties of Nuts 389

11.3.2 Nuts and Body Weight Control 389

11.3.3 Nuts and Cardiovascular Disease 389

11.3.4 Nuts and Diabetes 393

11.3.5 Nuts and Cancer 395

11.3.6 Application of Nuts in the Functional Food Industry 398

11.4 Tree Nuts and Allergy 399

11.5 Conclusion 401

References 401

$12 \quad$ Nuts as Sources of Nutrients 411

João C. M. Barreira, M. Beatriz P. P. Oliveira, and Isabel C. F. R. Ferreira

12.1 Prunus dulcis (Miller) D. A. Webb (almond) 411

12.1.1 Botanical Aspects and Geographical Distribution 411

12.1.2 Main Applications and Nutritional Overview 411

12.1.3 Major Components 412

12.1.4 Minor Components 417

12.2 Castanea sativa Miller (Chestnut) 418

12.2.1 Botanical Aspects and Geographical Distribution 418

12.2.2 Main Applications and Nutritional Overview 418

12.2.3 Major Components 418

12.2.4 Minor Components 419

12.3 Corylus avellana L. (Hazelnut) 420

12.3.1 Botanical Aspects and Geographical Distribution 420

12.3.2 Main Applications and Nutritional Overview 420

12.3.3 Major Components 420

12.3.4 Minor Components 421

12.4 Juglans regia L. (Walnut) 422

12.4.1 Botanical Aspects and Geographical Distribution 422

12.4.2 Main Applications and Nutritional Overview 422

12.4.3 Major Components 422

12.4.4 Minor Components 423

12.5 Conclusion 423

References 424 
$\mathbf{x}$ Contents

13 The Contribution of Chestnuts to the Design and Development of Functional Foods 431

Ariane Mendonça Kluczkovski

13.1 Introduction 431

13.2 Chestnut Composition 431

13.3 Biotechnology and Safety 435

13.3.1 Functional Properties and Health Effects 435

13.3.1.1 Antioxidants 436

13.3.1.2 Prebiotics 437

13.3.1.3 Gluten-Free Products 438

13.3.2 Functionality of Chestnut Products 439

13.4 Conclusion 440

References 441

14 Emerging Functional Foods Derived from Almonds 445 Isabela Mateus Martins, Qianru Chen, and C. Y. Oliver Chen

14.1 Introduction 445

14.2 Overview of Almond Nutrients 446

14.3 Health Benefits and Bioactions of Almonds 447

14.3.1 Cholesterol Reduction 447

14.3.2 Glucose Regulation 451

14.3.3 Antiinflammation 451

14.3.4 Antioxidation 453

14.3.5 Body Weight Control 456

14.3.6 Prebiotics 458

14.4 Development of Functional Foods with Almonds 459

14.5 Conclusion 462

References 462

Index 471 


\section{List of Contributors}

\section{Ryszard Amarowicz}

Division of Food Science,

Institute of Animal Reproduction and

Food Research of the Polish Academy of

Sciences, ul,

Poland

\section{Ana Maria Barata}

Instituto Nacional de Investigação

Agrária (INIAV),

Banco Português de Germoplasma

Vegetal (BPGV),

Portugal

\section{João C. M. Barreira}

Mountain Research Centre (CIMO),

School of Agriculture,

Polytechnic Institute of Bragança,

Portugal

\section{Carolina Barroetaveña}

Centro de Investigación y Extensión

Forestal Andino Patagónico CIEFAP,

Argentina

\section{Lillian Barros}

Mountain Research Centre (CIMO),

School of Agriculture,

Polytechnic Institute of Bragança,

Portugal

\section{Yaixa Beltrán}

Center for Studies on Industrial

Biotechnology (CEBI),

University of Oriente,

Cuba

\section{Albino Bento}

Mountain Research Centre (CIMO),

School of Agriculture,

Polytechnic Institute of Bragança, Portugal

\section{Rosa C. Bermúdez}

Center for Studies on Industrial

Biotechnology (CEBI),

University of Oriente,

Cuba

\section{Paula Cabo}

Mountain Research Centre (CIMO), School of Agriculture,

Polytechnic Institute of Bragança, Portugal

\section{Cristina Caleja}

Mountain Research Centre (CIMO), School of Agriculture,

Polytechnic Institute of Bragança, Portugal

\section{Montaña Cámara Hurtado}

Department of Nutrition and

Bromatology II,

Faculty of Pharmacy, Complutense

University of Madrid,

Spain

\section{Márcio Carocho}

Mountain Research Centre (CIMO), School of Agriculture,

Polytechnic Institute of Bragança, Portugal 
Ana Maria Carvalho

Mountain Research Centre (CIMO),

School of Agriculture,

Polytechnic Institute of Bragança,

Portugal

\section{Y. Oliver Chen}

Antioxidants Research Laboratory, Jean Mayer USDA Human Nutrition Research Center on Aging,

Tufts University, USA

\section{Qianru Chen}

Antioxidants Research Laboratory, Jean Mayer USDA Human Nutrition

Research Center on Aging,

Tufts University, USA

\section{Ana Ćirić}

University of Belgrade, Institute for

Biological Research "Siniša Stanković”,

Serbia

\section{Maria de Cortes Sánchez Mata}

Department of Nutrition and

Bromatology II,

Faculty of Pharmacy, Complutense

University of Madrid,

Spain

\section{Maria Inês Dias}

Mountain Research Centre (CIMO),

School of Agriculture,

Polytechnic Institute of Bragança,

Portugal

\section{Virginia Fernández-Ruiz}

Department of Nutrition and

Bromatology II,

Faculty of Pharmacy, Complutense

University of Madrid,

Spain

Isabel C. F. R. Ferreira

Mountain Research Centre (CIMO),

School of Agriculture,

Polytechnic Institute of Bragança,

Portugal
Isabelle Gaime-Perraud

IMBE Biotechnologies et Bioremediation

(IMBE-EBB),

Faculte St Jerome,

France

\section{Nora García}

Center for Studies on Industrial

Biotechnology (CEBI),

University of Oriente,

Cuba

\section{Patricia García Herrera}

Department of Nutrition and

Bromatology II,

Faculty of Pharmacy, Complutense

University of Madrid,

Spain

\section{Jasmina Glamočlija}

University of Belgrade, Institute for

Biological Research "Siniša Stanković",

Serbia

\section{YiGong}

Department of Food Science and

Technology,

College of Agricultural and

Environmental Sciences,

University of Georgia,

USA

\section{Yamila Lebeque}

Center for Studies on Industrial

Biotechnology (CEBI),

University of Oriente,

Cuba

\section{Gabriel Llauradó}

Center for Studies on Industrial

Biotechnology (CEBI),

University of Oriente,

Cuba

\section{Ricardo Malheiro}

Mountain Research Centre (CIMO),

School of Agriculture,

Polytechnic Institute of Bragança,

Portugal 


\section{Anabela Martins}

Polytechnic Institute of Bragança, School of Agriculture (IPB-ESA), Portugal

\section{Natália Martins}

Mountain Research Centre (CIMO), School of Agriculture,

Polytechnic Institute of Bragança, Portugal

\section{Maria Cruz Matallana González}

Department of Nutrition and

Bromatology II,

Faculty of Pharmacy, Complutense

University of Madrid,

Spain

\section{Isabela Mateus Martins}

Antioxidants Research Laboratory, Jean Mayer USDA Human Nutrition Research Center on Aging,

Tufts University,

USA

\section{Ariane Mendonça Kluczkovski}

Faculty of Pharmaceutical Sciences, Federal University of Amazonas, Brazil

\section{Patricia Morales}

Department of Nutrition and

Bromatology II,

Faculty of Pharmacy, Complutense

University of Madrid,

Spain

\section{Humberto J. Morris}

Center for Studies on Industrial

Biotechnology (CEBI),

University of Oriente,

Cuba

\section{Serge Moukha}

Department of Toxicology, UFR des

Sciences,

Pharmaceutiques-Université Bordeaux

Segalen,

France

\section{Beatriz P. P. Oliveira}

REQUIMTE/LAQV, Faculty of Pharmacy, University of Porto,

Portugal

\section{Ronald B. Pegg}

Department of Food Science and Technology,

College of Agricultural and

Environmental Sciences,

University of Georgia,

USA

José Pinela

Mountain Research Centre (CIMO),

School of Agriculture,

Polytechnic Institute of Bragança,

Portugal

\section{Brígida María Ruiz-Rodríguez}

Department of Nutrition and

Bromatology II,

Faculty of Pharmacy, Complutense

University of Madrid,

Spain

\section{Marina Soković}

University of Belgrade, Institute for

Biological Research "Siniša Stanković",

Serbia

\section{Dejan Stojković}

University of Belgrade, Institute for Biological Research "Siniša Stanković, Serbia

\section{Carolina V. Toledo}

Centro de Investigación y Extensión Forestal Andino Patagónico CIEFAP, Argentina

\section{Esperanza Torija Isasa}

Department of Nutrition and

Bromatology II,

Faculty of Pharmacy, Complutense

University of Madrid,

Spain 


\section{Preface}

The use of healthy ingredients is a natural way of preventing diseases and contributes to the increased use of natural matrices. This book focuses on the nutritional, chemical, and biological properties of natural matrices from the Iberian peninsula, mainly food products such as wild plants, mushrooms, chestnuts, and almond.

Society's attitude to food, as a natural and inevitable necessity, has altered in line with changes in social conditions and development of technology. Current consumers are interested in the composition, properties, safety, and health effects of food products. The desire to consume foods with high biological value from natural origins poses a huge challenge for modern food science and industry. In addition, the recent consumer interest in chemopreventive nutrition has increased the choice of food products (functional foods) with specific components (bioactive compounds). The current increase in the adoption of more active and healthy lifestyles needs to be followed by a concomitant response from all players in the food chain. The knowledge contained in this book will allow scientists and, in the longer term, lay members of society to gain a better understanding of the value that these products exhibit, focusing on their nutritional and chemical composition, bioactivity, and potential as functional foods.

Ongoing research on selected products will lead to a new generation of foods, and will promote their nutritional and medicinal use. Public health authorities consider prevention and treatment with nutraceuticals a powerful instrument in maintaining and promoting health, longevity, and life quality. The beneficial effects of nutraceuticals will undoubtedly have an impact on nutritional therapy; they also represent a growing segment of today's food industry. Therefore wild plants, mushrooms, and nuts have become interesting food products due to the increasing interest in the concept of "functional foods" with "health benefits."

Wild Plants, Mushrooms and Nuts: Functional Food Properties and Applications is a compendium of current and novel research on the chemistry, biochemistry, nutritional and pharmaceutical value of traditional food products, which are becoming more relevant in our current diet, for developing novel health foods and in modern natural food therapies. Topics covered range from their nutritional value, chemical and biochemical characterization, to their multifunctional applications as food with beneficial effects on health, through their biological and pharmacological properties (antioxidant, antibacterial, antifungal, and antitumor capacity, among others). 


\title{
Wild Plant-Based Functional Foods, Drugs, and Nutraceuticals
}

\author{
José Pinela ${ }^{1,2}$, Márcio Carocho ${ }^{1,3}$, Maria Inês Dias ${ }^{1,2}$, Cristina Caleja $a^{1,2}$, \\ Lillian Barros ${ }^{1}$, and Isabel C. F. R. Ferreira ${ }^{1}$ \\ ${ }^{1}$ Mountain Research Centre (CIMO), School of Agriculture, Polytechnic Institute of Bragança, Portugal \\ ${ }^{2}$ REQUIMTE/LAQV, Faculty of Pharmacy, University of Porto, Rua Jorge Viterbo Ferreira, no 228, 4050-313 Porto, Portugal \\ ${ }^{3}$ Department of Nutrition and Bromatology ll, Faculty of Pharmacy, Complutense University of Madrid, Plaza Ramón y Cajal, \\ s/n., 28040 Madrid, Spain
}

\subsection{Introduction}

Wild plants were originally the main element in the human diet, culminating in the different cultures and societies of today. However, the establishment of agriculture led to the decline of consumption of wild plants in comparison to the cultivars that could be grown every year (Grivetti \& Ogle 2000). Nevertheless, consumption of wild plants is still a tradition that remains in many cultures, either for their nutritional and health benefits or for sociocultural behaviors that characterize many societies (Groot et al. 2002; Pardo de Santayana et al. 2007; Schulp et al. 2014). As human health and nutrition are two of the pillars that sustain our survival, it is necessary to find new ways to support medical care, which can be found in the vast wild plant ecosystem (Heywood 2011).

Food with additional functional properties could be the future of health supplies for the world population, and thus food and drugs are increasingly seen as one matrix (Bernal et al. 2011). Functional foods, nutraceuticals, and drugs based on wild plants that are still unexplored are emerging as a response to the world market, which has been searching for new, better, and safer products.

Functional foods have a similar appearance to their traditional counterparts, but bring potential beneficial effects when consumed on a regular basis in a varied diet. On the other hand, nutraceuticals are substances that have positive physiological effects on the human body, being consumed in unit dose forms such as tablets, capsules or liquids, allowing the delivery of a concentrated bioactive agent and providing a dose that could not be obtained from a normal food intake (Gulati \& Ottaway 2006; Hasler 2000). Both the functional food and nutraceutical sectors have been growing significantly in Europe but in the European Union nutraceuticals are not 
considered as a specific food category with a series of rules and guidelines to define the product itself, obeying the general regulations on food safety, traceability, recall, and notification (Coppens et al. 2006; Gulati \& Ottaway 2006). In terms of the health claims associated with functional foods, relating to Regulation (CE) No. 1924/2006 of the European Parliament on nutritional claims and health properties of food, it is possible to classify a functional food under very strict rules and conditions. In addition to the legislation required for all foodstuffs, scientific evidence of the health claims regarding the relevant food will be mandatory for all new products (BechLarsen \& Scholderer 2007). In the United States, on the other hand, the Food and Drug Administration (FDA) defines the product's category depending on its characteristics, nutraceuticals being regulated as a food and beverage product and dietary supplement, covered by several safety issues, health claims, labeling, and good manufacturing practices (Milner 2000; Wrick 2005).

Concerning drug development, the market also requires safer products due to increasing worldwide concern about synthetic chemical compounds. In that respect, wild plant-based drugs are now in the forefront of the therapeutic agents used for human health, taking into account their high efficiency and low toxicity (Bhardwaj et al. 2014; Carocho \& Ferreira 2013a).

In this chapter, wild plants commonly used as functional foods will be reviewed. For nutraceuticals, the emerging concept, their applications and novel formulations will be described, and also some products already available on the market. The relationship between the bioactive phytochemical and the active principle will be explained, listing the common formulations in wild plant-based drugs and the different therapeutic targets that can be explored.

\subsection{Wild Plants and Functional Foods}

\subsubsection{The Concept and Recent Trends in Functional Foods}

In the first half of the twentieth century, the focus of nutritional science was on establishing the minimum requirements for essential nutrients that ensure the avoidance of deficiency diseases (MMWR 1999). Nowadays, these concepts are changing significantly in the industrialized world. We are progressing from a concept of "adequate nutrition" to one of "optimal nutrition" (Ashwell 2003); from a matter of survival, satisfying hunger, and ensuring food safety to an emphasis on the potential for foods to promote health, in terms of both preventing nutrition-related diseases and improving physical and mental wellbeing (Nöthlings et al. 2007; Takachi et al. 2008). In addition, consumers are increasingly better informed about the subject than they were in the past. As a result, their expectations of obtaining health benefits from the food they eat are also increasing (Diplock et al. 1999). These changes can be explained by some significant trends in our present society, namely rapid advances in science and technology, the rising costs of healthcare, the increase in the numbers of elderly people and in average life expectancy, changes in food laws affecting label and product claims, and people's desire for a better quality of life (Roberfroid 2007).

The primary role of food is to provide nutrients to meet human metabolic requirements and to give the consumer a feeling of satisfaction and wellbeing through 
hedonistic attributes such as taste. In addition to this, food can fulfill specific physiological functions in the human body (Li et al. 2014a; Zhang et al. 2015). In fact, food can not only help to achieve optimal health and development, but it might also play an important role in reducing or preventing the risk of disease. According to the World Health Organization (WHO) and Food and Agriculture Organization (FAO), several dietary patterns along with lifestyle habits constitute major modifiable risk factors in relation to the development of coronary heart disease, different types of cancer, diabetes, obesity, osteoporosis, and periodontal disease (WHO 2003). Foods with these properties were first regulated in Japan in 1981 as Foods for Specified Health Use (FOSHU) (Hasler 2002; Ohama et al. 2006). Later, in Europe, the project Functional Food Science in Europe (FUFOSE) was created to assess critically the science base required to provide evidence that specific nutrients and food components beneficially affect target functions in the human body (Tijhuis et al. 2012). Currently, this kind of food is generally referred to as "functional food," if in accordance with the definition given below.

Although there is no universally accepted definition for functional foods (Hasler 2002), and because functional foods are more of a concept than a well-defined group of food products, here we present the definition described previously by Diplock et al. (1999). According to these authors, a food can be regarded as "functional" if it is satisfactorily demonstrated to affect beneficially one or more target functions in the human body, beyond adequate nutritional effects, in a way relevant to either an improved state of health and wellbeing and/or disease risk reduction. These foods must remain foods in appearance and they must demonstrate their effects in amounts that can normally be expected to be consumed in the usual diet, i.e. they are not pills or capsules, but part of a normal food pattern. Additionally, a functional food can be a natural or unmodified food, or one to which a component has been added or removed by technological or biotechnological means. It can also be a food where the nature of one or more components has been modified, the bioavailability altered, or any combination of these possibilities. Additionally, a functional food might be functional for all members of a population or for particular groups only. It is also important to note that, along with the nonuniversal definition, global markets also do not have the same regulatory systems for these foods (Bagchi 2014).

Functional food science is still at an early stage in its development. However, since knowledge about the functional effects of foods is increasing and the functionality of particular foods and food components is more extensively recognized, technology will have a continuing role to play in making those foods and food components more widely available and accessible (Howlett 2008). On the other hand, it is now known that genetic factors influence the relationship between diet and disease, and the ways in which different protective and risk factors can act. Furthermore, it is possible to visualize differences between genetic profiles of individuals at the molecular level and understand how they relate to differences between those individuals' responses to physiological factors. Thus, in the near future, knowledge gained in the fields of genomics, proteomics, and metabolomics (collectively known as "omics") will be of great importance for the development of functional foods and to create customized diet programs, as well as verifying the influence of dietary factors on human health and disease, which can lead to the identification of new food functionality routes (Howlett 2008). 


\subsubsection{Classification and Development of Functional Foods}

Functional foods represent one of the most interesting and active areas of research and innovation in the food industry (Annunziata \& Vecchio 2011). Their design and development, besides being an expensive process (Betoret et al. 2011), is a key issue, as well as a scientific challenge, which should rely on basic scientific knowledge relevant to target functions and their possible modulation by food components (Diplock et al. 1999). It is possible to separate them into natural (or nonaltered) and modified functional foods. But whether modified or not, they should always be safe, without any consideration of a trade-off between health benefit and health risk. More specifically, and according to the definition of functional foods presented before, they can be classified as:

- nonaltered products: foods naturally containing increased content of nutrients and/ or health-promoting compounds

- fortified products: foods wherein the content of the existing components is increased

- enriched products: foods to which a component not normally found is added to provide benefits

- altered products: foods in which a component is removed or replaced by an alternative component with favorable properties

- enhanced commodities: the food composition is altered by changing the raw commodity, i.e. one of the components is enhanced through special growing conditions, breeding, or biotechnological means.

Although the functional food industry is growing steadily worldwide, the successful commercialization of new functional foods remains a challenge, especially due to the need for a strategic approach to their production processes (Howlett 2008). For this reason, during the development or reengineering of modified functional foods, it is necessary to take into account many variables, such as sensory acceptance, convenience, stability, chemical and functional properties, and price (Betoret et al. 2011; Granato et al. 2010). In fact, the relationship "structure-property" needs to be noted, once the functional effect depends on the active component gaining access to the functional target site. However, foods are mostly complex mixtures that can trap active compounds, modulate their release, or inhibit their activity. Thus, the food matrix in its raw state, after culinary preparation, or storage can have a significant influence on the activity or release of the key components. According to Betoret et al. (2011), the design of appropriate food vehicles to maintain the active form until the time of consumption, and to deliver this form to the desired target site within the organism, is vital to the success of functional foods.

Betoret et al. (2011) grouped the available technologies for functional foods development into three main categories. The first group is formed by the most commonly used technologies for functional foods development, including technologies traditionally used in food processing, formulation, and blending as well as for cultivation and breeding. The second group, constituted by methodologies that form a structure to try to prevent the deterioration of physiologically active compounds, includes microencapsulation, edible films and coatings, and vacuum impregnation technologies. The third group, formed by recent technologies that are intended to design functional foods aimed at personalized nutrition, is the one that has grown significantly in recent years. 


\subsubsection{Wild Plants Used as Functional Foods}

Plants are irreplaceable food resources for humans. Their interchangeable use as foods and as medicines, or healthy foods, has been part of human heritage since prehistoric times. Despite only a small number of existing plant foods having substantial clinical documentation of their health benefits, an even smaller number (and including only cultivated plants) have surpassed the rigorous standard of "significant scientific agreement" required by the FDA and EFSA for authorization of a health claim (Hasler 2002). Oat soluble fiber, soluble fiber from psyllium seed husk, soy protein and sterol and stanol ester-fortified margarine are plant-based foods currently eligible to bear an FDAapproved health claim (Hasler 2002). However, there is growing clinical research supporting the potential health benefits of various plant foods (including wild plants) or food constituents that currently do not have approved health claims, and thus are described as having "moderately strong evidence." Examples include berries, leafy vegetables, garlic, grapes and chocolate, among others listed in Table 9.1.

Table 9.1 presents wild edible plants that have been investigated due to their claimed functional properties. These plants are interesting sources of physiologically active ingredients which are linked to various beneficial health effects. Various berries, including elderberry, bilberry, cranberry, blackberry, raspberry, and wild strawberry, stand out as a source of anthocyanins, proanthocyanidins, flavonols, phenolic acids, and vitamins, among other bioactive compounds. These molecules, isolated or in combined extracts, have antioxidant, antiinflammatory, anticarcinogenic, cardioprotective, and antibacterial properties (Barros et al. 2011a; Bowen-Forbes et al. 2010; Madhavi et al. 1998; Najda et al. 2014; Sidor \& Gramza-Michalowska 2014; Singh et al. 2009). Wild strawberry fruits harvested from natural habitats were highlighted by Najda et al. (2014) as containing more anthocyanins and higher antioxidant activity than those from cultivation. Likewise, Lv et al. (2014) showed that the wild litchi cultivar Hemaoli has high total phenolic and flavonoid content in comparison to one of the main market cultivars. This fruit also has high levels of carotenoids and vitamin $C$, which contribute to its antioxidant, antiapoptotic, and hepatoprotective effects (Bhoopat et al. 2011; Huang et al. 2010a; Lv et al. 2014). Physalis (Physalis spp.) is another berry with claimed functional properties. Physalins, withanolides, sterols, polysaccharides, and flavones are compounds present in this golden berry. According to Li et al. (2014c), it has antiinflammatory, antioxidant, antitumor, hypoglycemic, and analgesic properties.

Other plants, like the root of beet (Beta spp.), have antioxidant, hepatoprotective, anticancer, and antiproliferative activity in MRC5 and MCF-7 cell lines, antihypertensive, and hypoglycemic effects. These health benefits are conferred by the high content of phenolic acids, flavonoids, betalains, minerals (P, Mg, Fe, $\mathrm{Zn}, \mathrm{Ca}$, and $\mathrm{Na}$ ), folic acid, biotin, and soluble fiber (Ninfali \& Angelino 2013; Vulić et al. 2014; Wootton-Beard \& Ryan 2011). In turn, ginger (Zingiber officinale Rosoe) has been described as a source of gingerols (6-gingerol), shogaols (6-shogaol), fiber, and flavonoids, as well as having antioxidant, antiinflammatory, antithrombotic, cholesterol-lowering, analgesic, antipyretic, and hypotensive effects (Mojani et al. 2014; Thomson et al. 2002).

Regarding leafy vegetables, the aerial parts of water blinks (Montia fontana L.) have high amounts of tocopherols and vitamin $C$, compounds that provide antioxidant benefits (Morales et al. 2012; Pereira et al. 2011), while watercress (Nasturtium officinale W.T. Aiton) is a rich source of phenolic compounds and minerals (P, Mg, $\mathrm{Ca}$, and $\mathrm{Mn}$ ) 


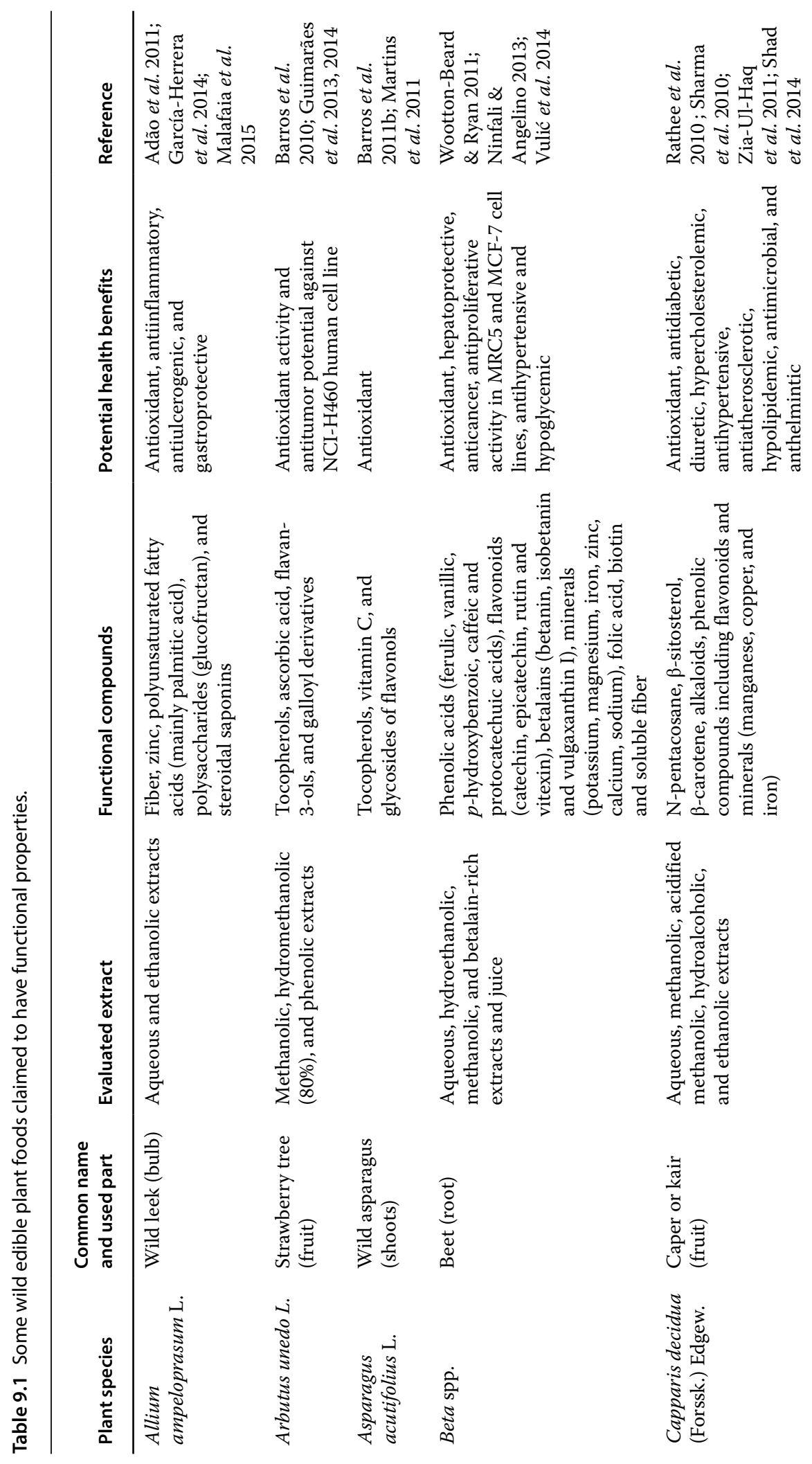




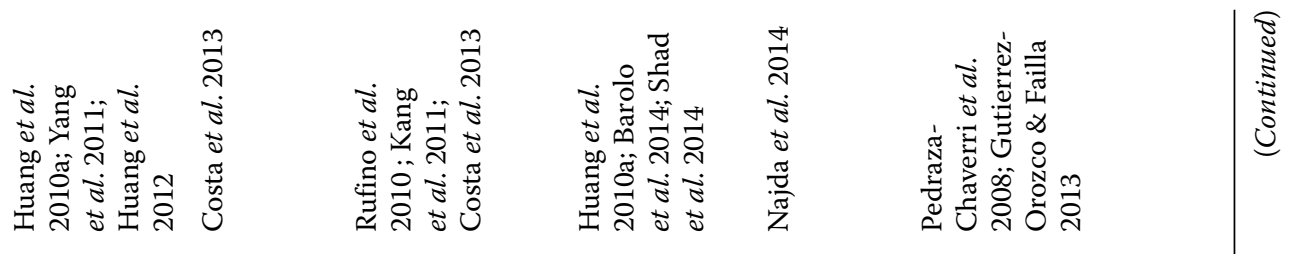
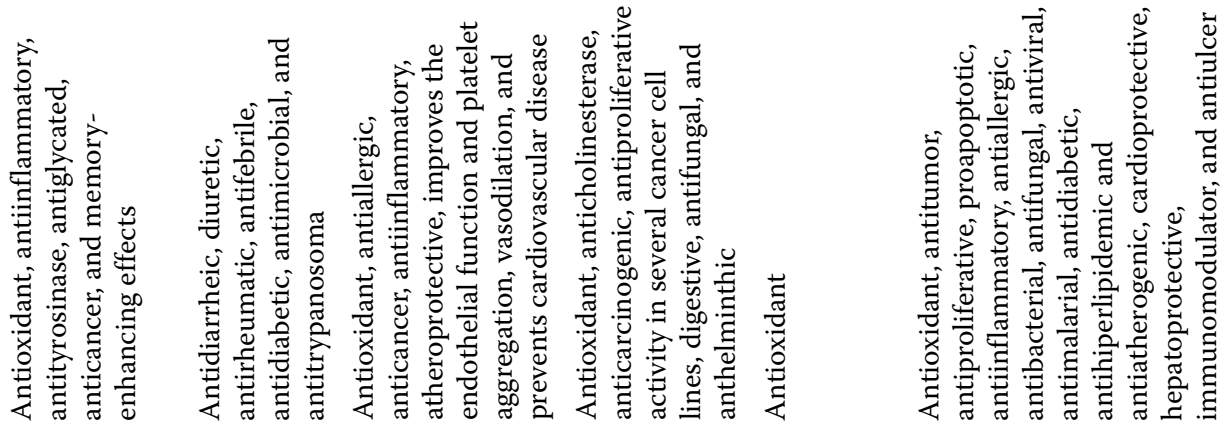

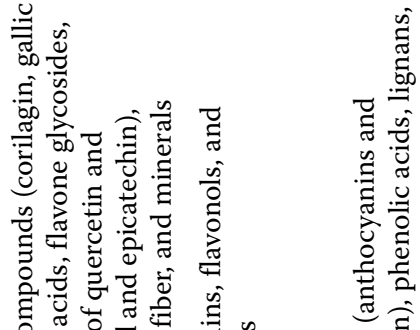

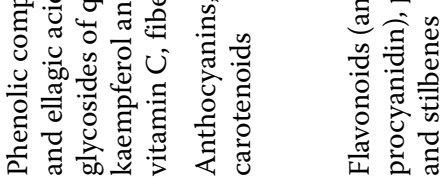

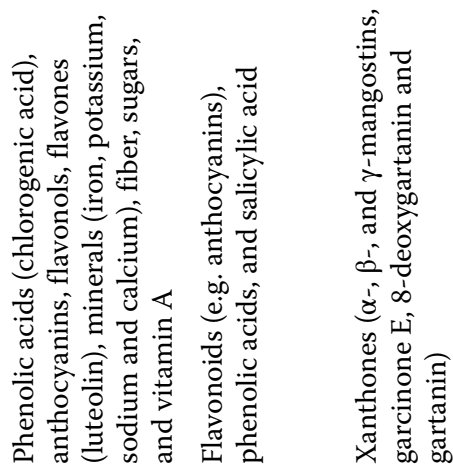

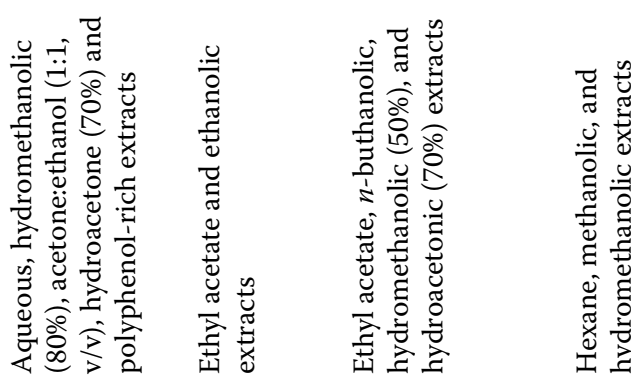

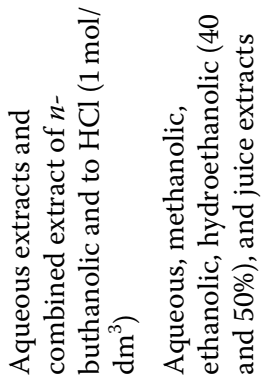

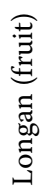

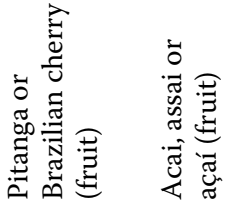

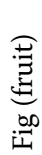

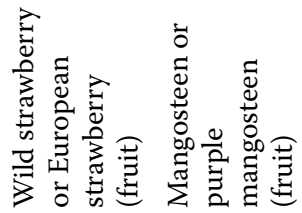

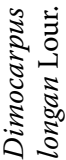
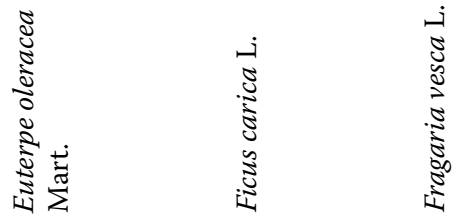

吾 


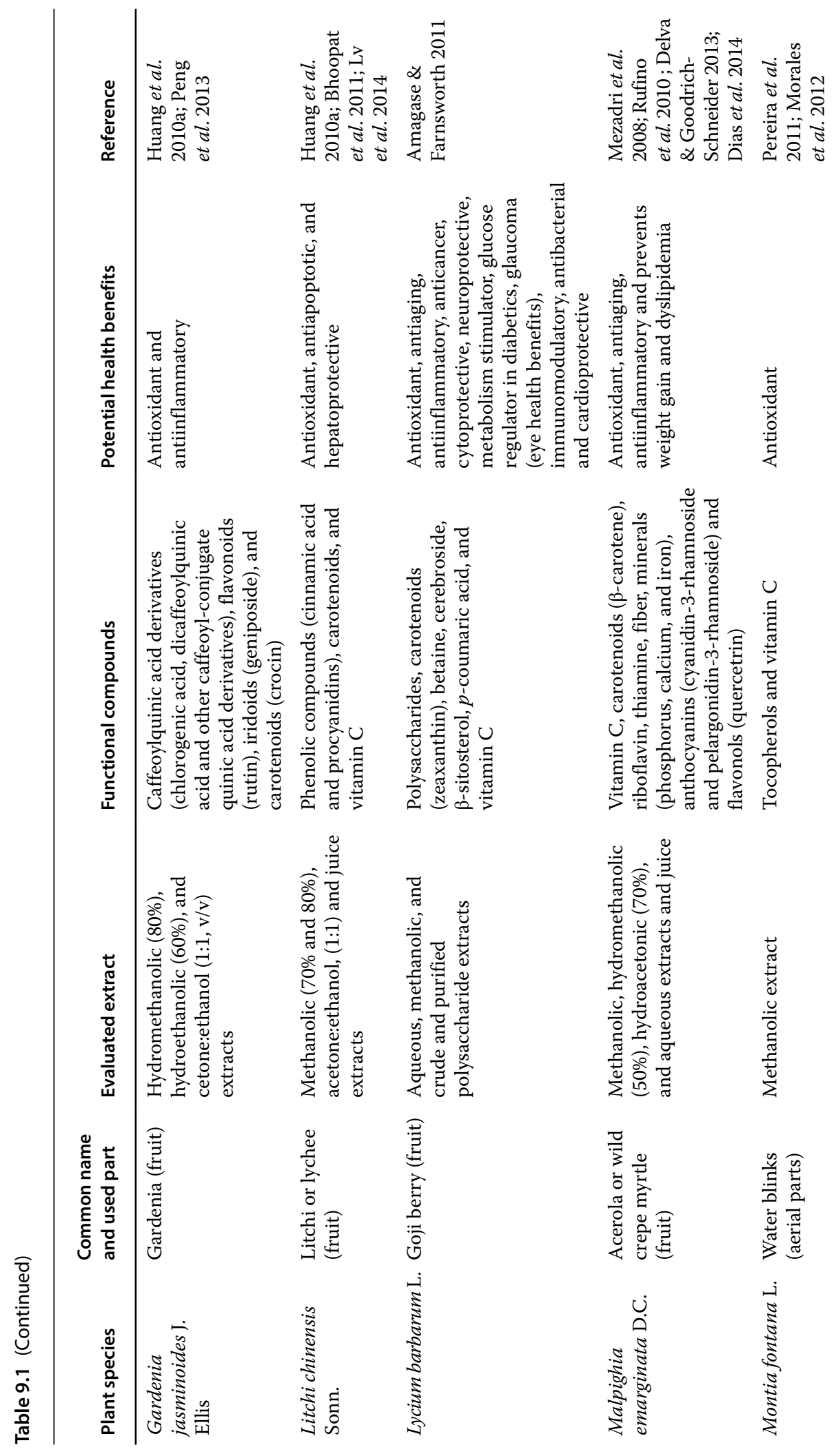




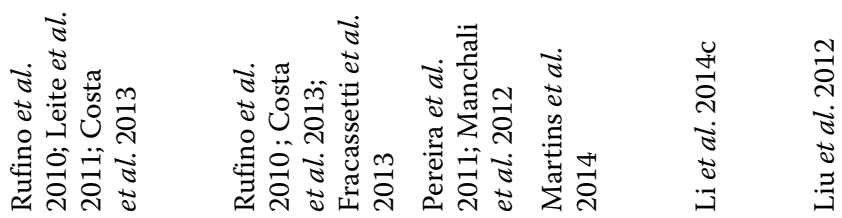

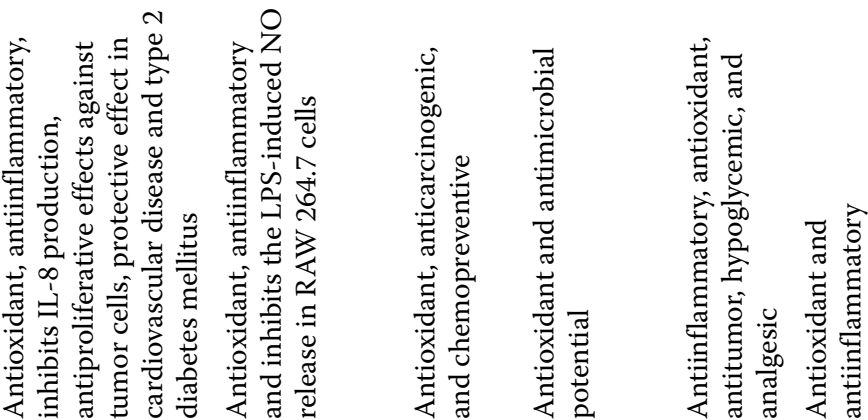

总

की

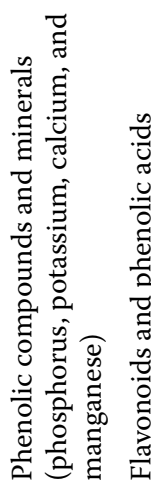

宊

弟官

포

कृ :

बै

s 过

范茟

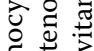

起

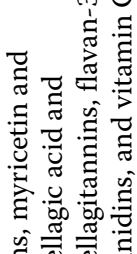

产 $\frac{\Xi}{\sigma}$

जี के

तัّ

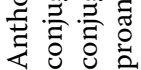

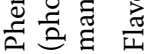

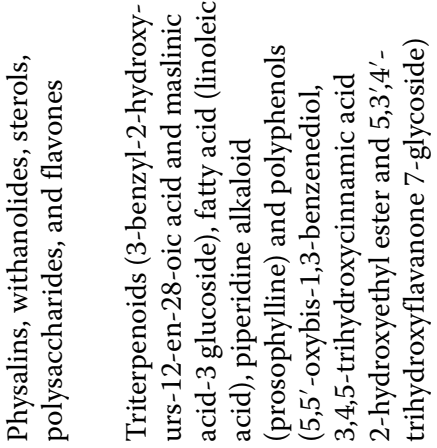

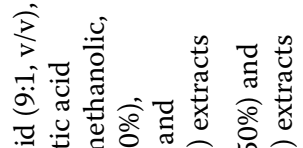

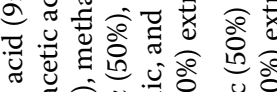

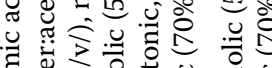

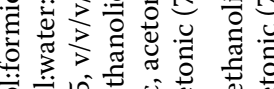

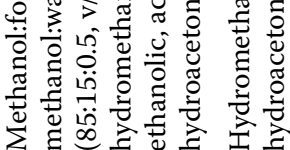

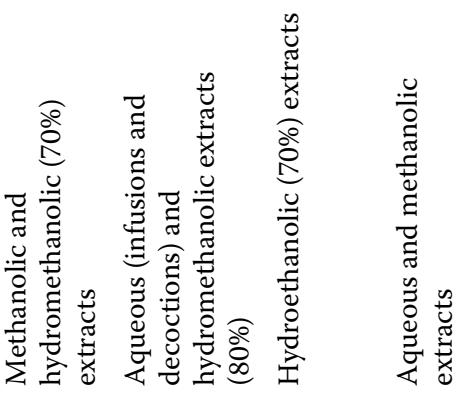

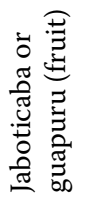

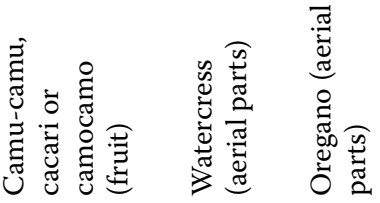

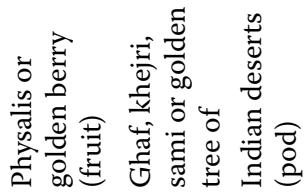

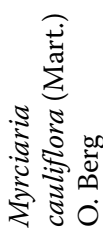

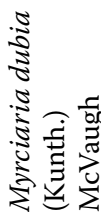

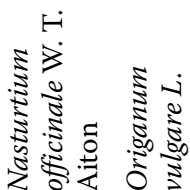

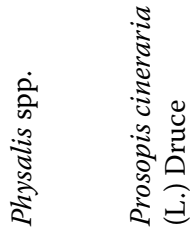




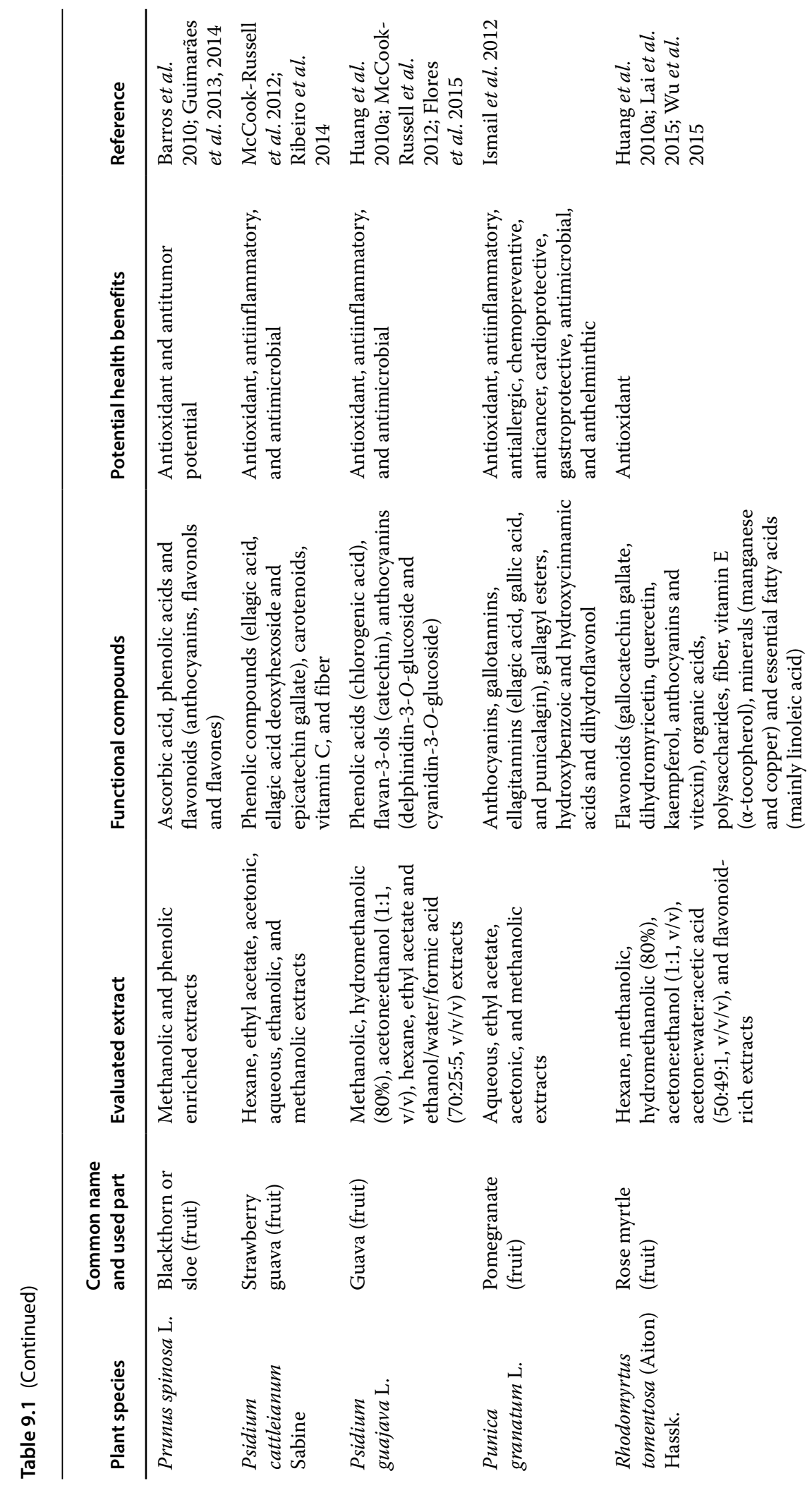




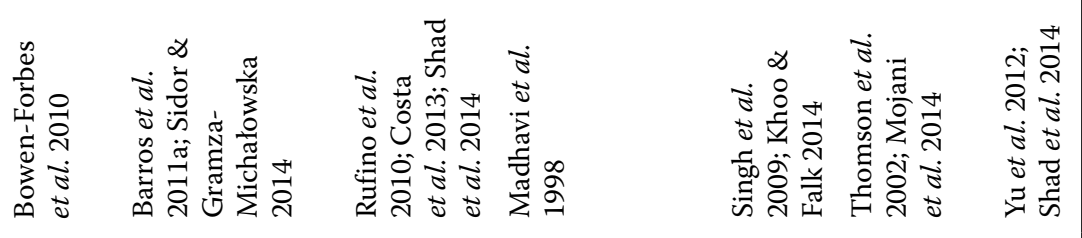

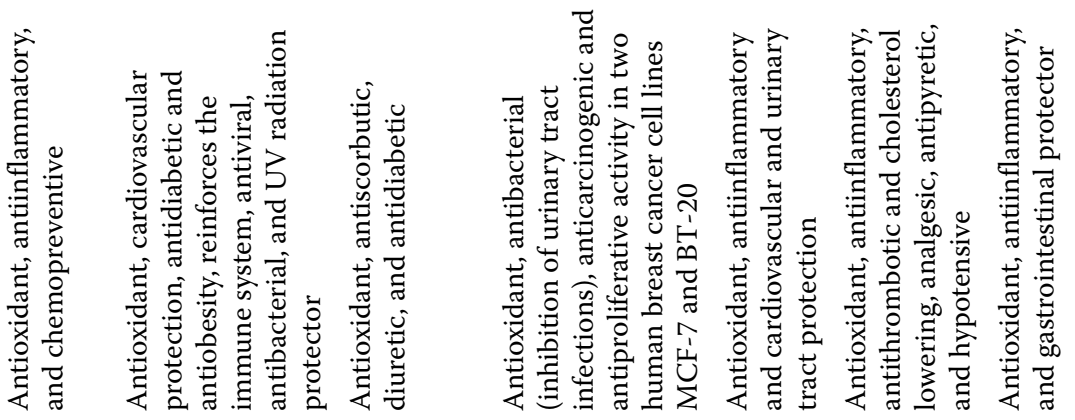

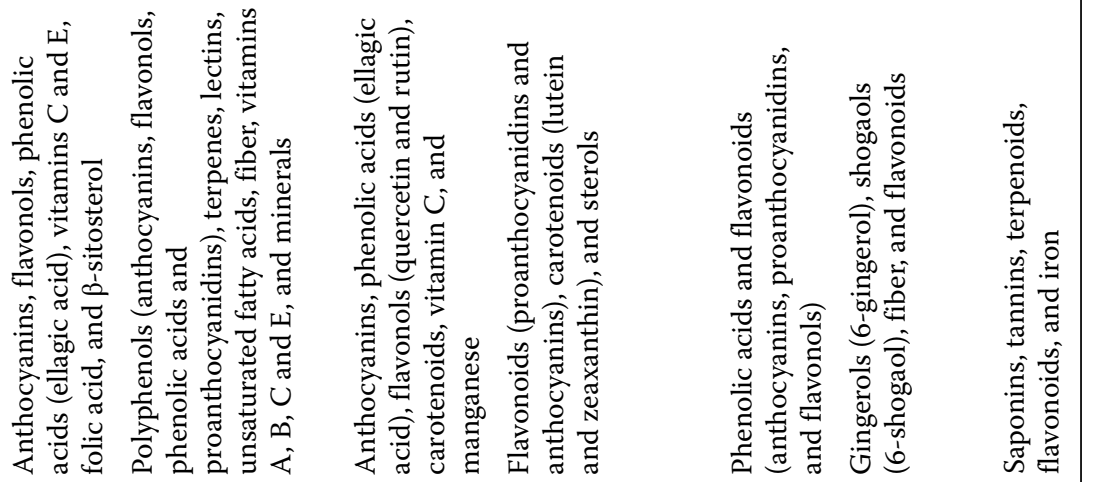

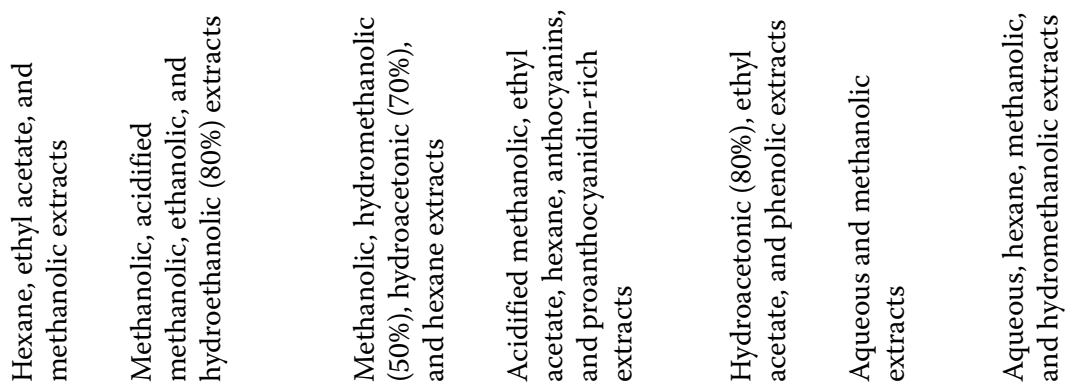

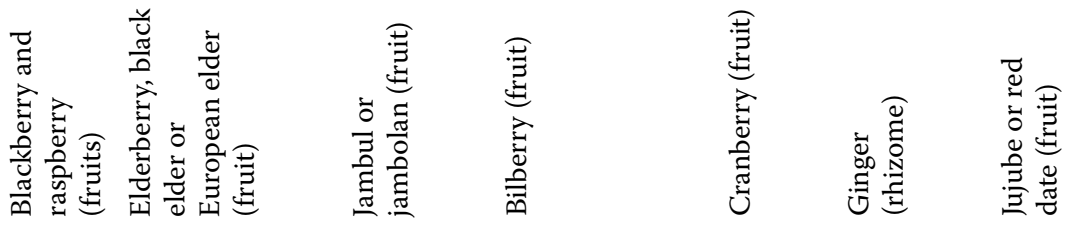

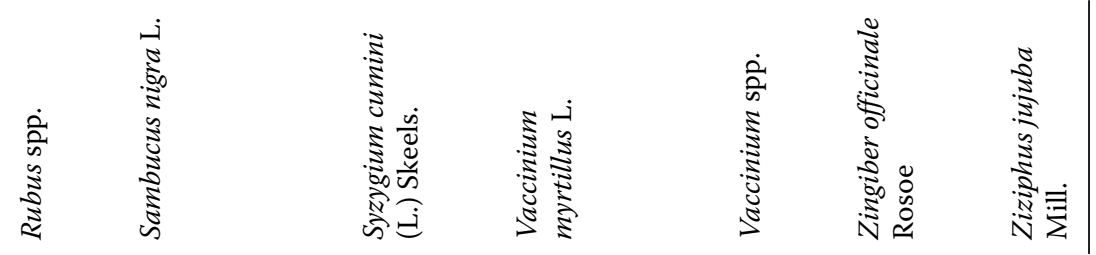


which confer its claimed antioxidant, anticarcinogenic, and chemopreventive effects (Manchali et al. 2012; Pereira et al. 2011). The aerial parts of oregano (Origanum vulgare L.), prepared in infusions, decoctions or hydromethanolic extracts (80\%), have antioxidant and antimicrobial potential probably related to flavonoids and phenolic acids (Martins et al. 2014).

Today, aggressive marketing highlighting the health-promoting benefits of mangosteen, acai, acerola or goji berry, among other fruits, bulbs, roots, seeds or leafy vegetables presented in Table 9.1, has resulted in their classification as "superfruits" or "superfoods." Scientific research carried out in recent years proves their effectiveness as healthy foods, and due to high profits, the food and pharmaceutical industries are increasingly interested in developing new products based on these plants.

However, in addition to edible plant parts, wild nonedible parts or plants can also be used as a source of health-promoting ingredients. Thus, medicinal and aromatic plants play an important role in the development of new or improved functional foods, as well as nutraceuticals. At the research level, some wild plant extracts are being incorporated into food products to increase their health-promoting properties. Martins et al. (2014) formulated new yogurts based on phenolic extracts of wild blackberry (Rubus ulmifolius Schott) flowers. The authors microencapsulated the hydroalcoholic extract in an alginatebased matrix and incorporated this into a yogurt to achieve antioxidant benefits. Recently, Caleja et al. (2015) improved the antioxidant properties of cottage cheese by the incorporation of fennel (Foeniculum vulgare Mill.) decoction (phenolic-enriched extract), improving not only functionality of the final product but also preservation effectiveness due to the antimicrobial potential of fennel.

Carocho et al. (2015a) transformed the Portuguese "Serra da Estrela" cheese into a functional food by incorporating dried chestnut (Castanea sativa Mill.) flowers or lemon balm (Melissa officinalis L.) plants, as well as their decocted extracts. The functionalized cheeses showed higher antioxidant activity, especially lipid peroxidation inhibition, bringing benefits both for consumers (healthier product) and producers (added-value product). The same authors also functionalized the Portuguese traditional cakes "económicos" by incorporation of dried chestnut (C. sativa) flowers or decoctions prepared from them (Carocho et al. 2015b). The final product showed increased antioxidant activity and phenolic content, without causing visible changes in inner and outer appearance.

\subsection{Wild Plant-Based Nutraceuticals}

\subsubsection{The Emerging Concept and Applications of Nutraceuticals}

A new generation of processed food is coming, which is a controversial subject for many people. Nutraceutical products represent a fast-growing sector within the food industry, aiming to increasingly attract the buyer to consume these novel dietary supplements and phytotherapeutic products. It is expected that in the near future, "food for special dietary needs," such as soups, smoothies, processed meat, bread and sausages, among others, will be enriched with nutraceutical formulations (Andlauer \& Furst 2002; Regulation (EC) No. 2002/46).

Nutraceuticals can be defined as diet supplements that contain bioactive compounds or extracts, prepared from raw natural matrices that will provide a higher dosage that 
could not be obtained from normal food products and functional foods (DeFelice 1992; Espín et al., 2007; Zeisel 1999). Directive 2002/46/EC of the European Parliament and Council, on the approximation of laws of Member States relating to food supplements, defines "food supplements" as foodstuffs with the purpose of supplementing the normal diet and which are concentrated sources of nutrients or other substances with a nutritional or physiological effect, alone or in combination, marketed in dose form, such as capsules, pastilles, tablets, pills, sachets of powder, ampoules of liquids, drop dispensing bottles, and other similar forms of liquids and powders designed to be taken in measured small unit quantities (Regulation (EC) No. 2002/46).

The health industry is using nutraceutical formulations as complements to prevent some diseases. Some authors have stated that any food or parts of foods can be considered nutraceutical compounds, as long as their beneficial health and nutritional claims are proved scientifically (Braithwaite et al., 2014; McNamara, 1997; Ross, 2000). On the other hand, Gulati and Ottaway (2006) and Espín et al. (2007) distinguished nutraceuticals as components that are often consumed in unit dose forms such as tablets, capsules or liquids. They can be isolated nutrients or herbal products presented in pharmaceutical forms or processed products like cereals, smoothies, and soups for special diet requirements (Andlauer \& Furst 2002; Braithwaite et al. 2014; Regulation (EC) No. 2002/46).

The concept of nutraceuticals is relatively recent, only appearing in the 1990s with the first publications and patents related to the subject (Figure 9.1). However, the increasing number of publications from academics (through articles and reviews) and industry (through patents) is notable. This can be explained by the fact that there is increasingly market demand for new, better, and safer food products. However, regarding plantbased nutraceuticals, the number of articles (and reviews) and patents is very low (see Figure 9.1) although it is growing. Many of the primary studies on nutraceuticals were made with individual compounds with known beneficial effects, but there is now interest in exploring the synergisms existing within plant extracts and incorporating them into nutraceuticals or modified functional food.

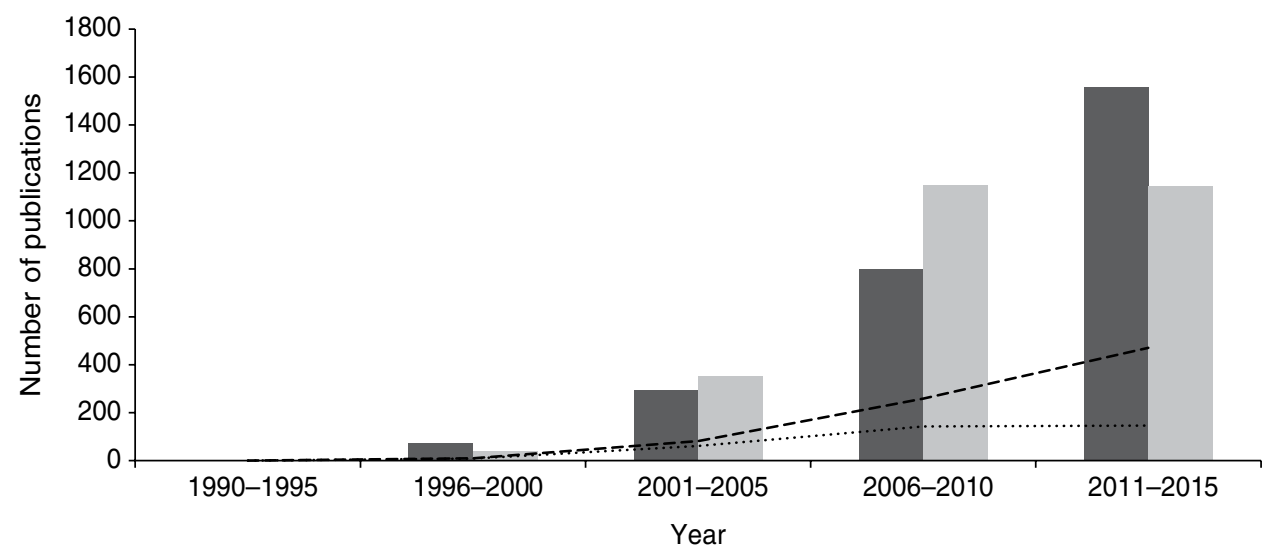

Figure 9.1 Number of research articles and reviews (. and - - -), and patents ( - and.........) published in the period from 1990 to 2015 regarding nutraceuticals and nutraceuticals formulated with plant material, respectively (obtained on Web of Science, January 2015; keyword: nutraceutical; nutraceutical + plant). 
Therefore, the development of legislation that regulates the production of nutraceutical formulations, their labeling and market supply is crucial. In January 2002, the European Food Safety Authority (EFSA) established Regulation (EC) No. 178/2002, setting down the general principles and requirements for food law. This Regulation also contains procedures for food safety, increasing the health protection of consumers. These guidelines are applied to all food products, including those with added functional properties, such as nutraceuticals and functional foods. From the perspective of the global pharmaceutical and medical industry, nutraceutical products are dietary supplements (Kwak \& Jukes 2001). Specific regulation of nutraceutical products is still very patchy; in European law they have no specific category, being considered under the same parameters used for dietetic foods, dietetic supplements, and food supplements (Coppens et al. 2006; Regulation (EC) No. 2002/46) or even under medicinal classification (Gulati \& Ottaway 2006). In the USA, nutraceuticals are considered only as dietary supplements (Bernal et al. 2011; Espín et al. 2007). The differences between European and USA regulation may be due to cultural, historical, and traditional backgrounds (Gulati \& Ottaway 2006). However, the development of specific legislation in Europe is necessary to ensure food safety for consumers and to prove that nutraceuticals are safe and scientifically accepted, and this may dictate the future success of these products (Braithwaite et al. 2014; Byrne 2003).

Recent research has shown very promising prospects for different natural ingredients added to food products, creating benefits for consumers' health and added value for manufacturers (Coppens et al. 2006). Many of the published papers on nutraceuticals are focused on their beneficial health properties (Bernal et al. 2011), for instance their ability to decrease the development of heart disease (Garcia-Rios et al. 2013; Giordano et al. 2012; Izzo et al. 2010; Scicchitano et al. 2014) such as hypercholesterolemia (Mannarino et al. 2014), and also for the prevention and treatment of prostate cancer (Li et al. 2014b). Nutraceutical formulations have been proved to be safe and well tolerated, but further studies are required to assess the decreasing of secondary effects of nutraceuticals when compared to analogue commercial drugs for the treatment of certain diseases (Bernal et al. 2011; McAlindon 2006).

\subsubsection{Recent Advances in Formulations for Nutraceuticals}

Due to the difficulty in the classification of nutraceuticals, we are faced with two types of products: nutraceuticals in the form of dietary supplements (tablets, capsules, solutions, syrups, powders, chewing tablets, among others) and those in the form of free or encapsulated extracts/compounds to be inserted into a food matrix (i.e. used to develop functional foods). For that reason, the formulation of nutraceuticals involves a wide range of methodologies and techniques, from the most used (tableting) to the newest and most advanced, such as microencapsulation complemented with nanotechnology.

First, it is necessary to ensure the safety and quality of the nutraceutical product. The chemical, nutritional, and bioactive characterization of the compound/extract that will be part of the formulation is required, as well as control of the dosage. For this, some advanced analytical techniques are used such as mass spectrometry (MS), nuclear magnetic resonance (NMR), high-performance liquid chromatography (HPLC), capillary electrophoresis (CE), and gas chromatography (GC), among others (Bernal et al. 2011; Sener \& Orhan 2005). 
The vast majority of nutraceutical formulations are designed for oral administration. Braithwaite et al. (2014) reported a description of some new nutraceutical formulation strategies to improve dosage, design, and delivery of the bioactives. From liposomal carriers, electrospun fiber mats, microsponges and nanoesponges, cyclodextrin complexations to biodegradable hydrogels, all these technologies prove the importance of nutraceuticals in today's economy, with a growing investment by the industry in new formulations that respond to market demand. Second-generation nanocrystals, another new formulation, are an emerging technology for the delivery of poorly soluble bioactives. They are mostly used for drug delivery to solve poor solubility and bioavailability. However, they also represent a reliable response for the delivery of many nutraceutical compounds already on the market, such as antioxidants. The main advantage of nanocrystal systems is the capacity to be applied via oral, intravenous, dermal, mucosal, ocular and even pulmonary routes (Shegokar \& Müller 2010).

It is important to realize that nutraceutical formulations go far beyond diet products or products enriched with a certain bioactive compound. Formulations are already on the "micro" and "nano" scales, which can be incorporated in food matrices but also in pharmaceutical formulations, serving as a complement to traditional medicine. Microencapsulation complemented with nanotechnology appears to overcome problems related to the use of free bioactives but also to provide controlled target delivery release (Braithwaite et al. 2014; Dias et al. 2015 Ezhilarisi et al. 2013; Huang et al. 2010b). Nanoscale delivery systems have the advantages of improving solubility, masking undesirable flavors and smells, and preventing the degradation of the bioactive compounds; they provide a triggered controlled release and, most important of all, increased bioavailability by prolonging contact within the gastrointestinal tract (Cerqueira et al. 2014). Microemulsions, for instance, are one of the most used techniques for the solubilization and transport of water and oil-insoluble compounds, presenting easier formulation and manufacture and also high stability during storage (Spernath \& Aserin 2006).

Food protein-based materials can also be used at "micro" and "nano" scales, depending on the type of encapsulation methodology used to produce the capsules and also the objective of the work. Proteins present the ability to form gels and emulsions due to their functional properties, which makes them appealing to the industry and academia for the encapsulation of nutraceuticals (Chen et al. 2006). Hydrocolloids fibers are being proposed to encapsulate nutraceutical compounds and extracts; they are nontoxic, inexpensive, and generally recognized as safe (GRAS). Furthermore, since they are complex carbohydrates, consumption on a regular basis showed health benefits for cardiovascular disease and diabetes (Janaswamy \& Youngren 2012). Researchers are also developing formulations linking nutraceuticals with drugs to enhance efficacy and reduce dosage and side-effects of chemical compounds (Braithwaite et al. 2014).

\subsubsection{Examples of Nutraceuticals Based on Wild Plants}

For economic and ecological sustainable reasons, the FAO recommends the cultivation of medicinal and aromatic plants that represent a genetic pool of raw material with better control of biotic and abiotic factors, allowing the standardization of the final product (Schippmann et al. 2002). For that reason all the listed examples in Table 9.2 are 


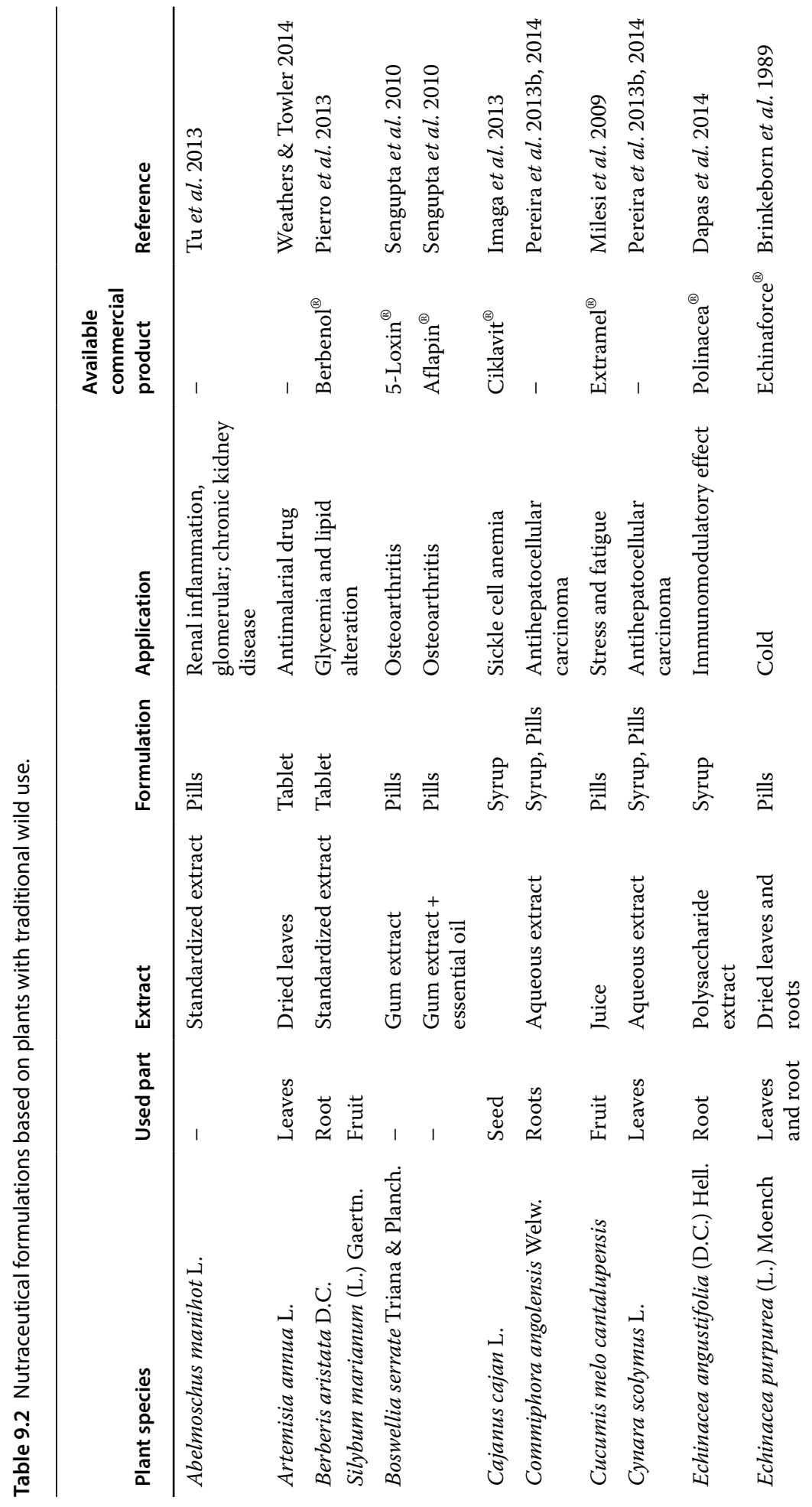




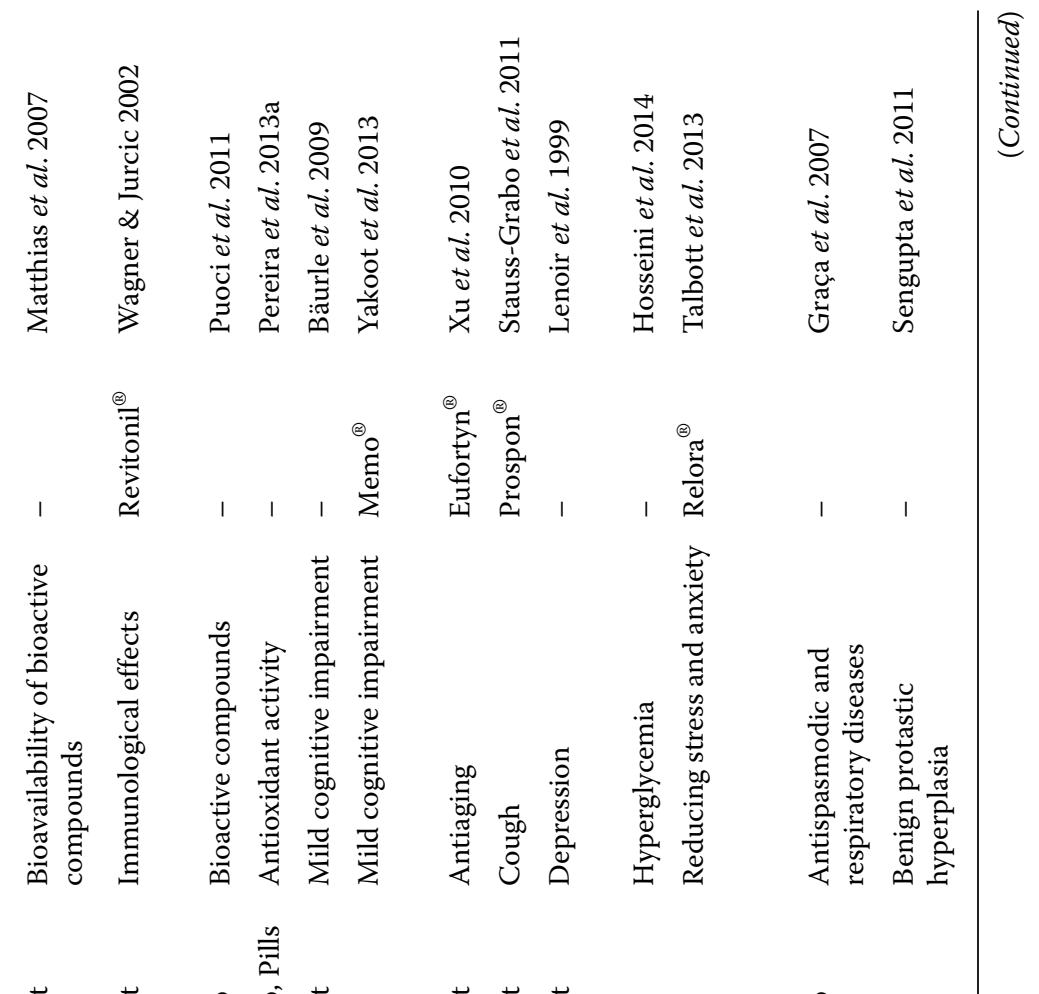

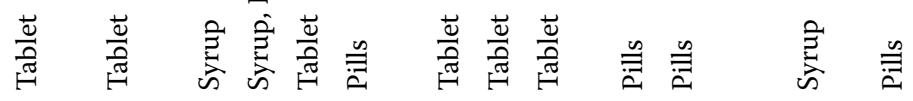

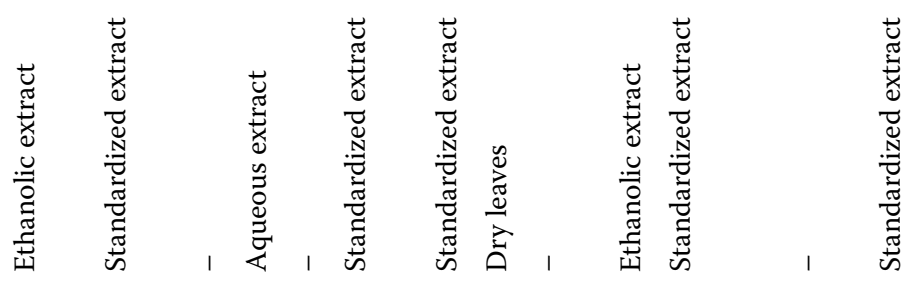

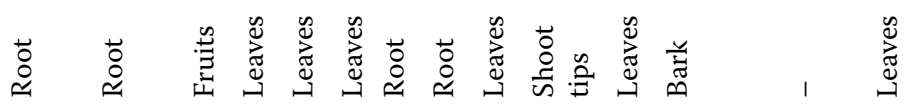

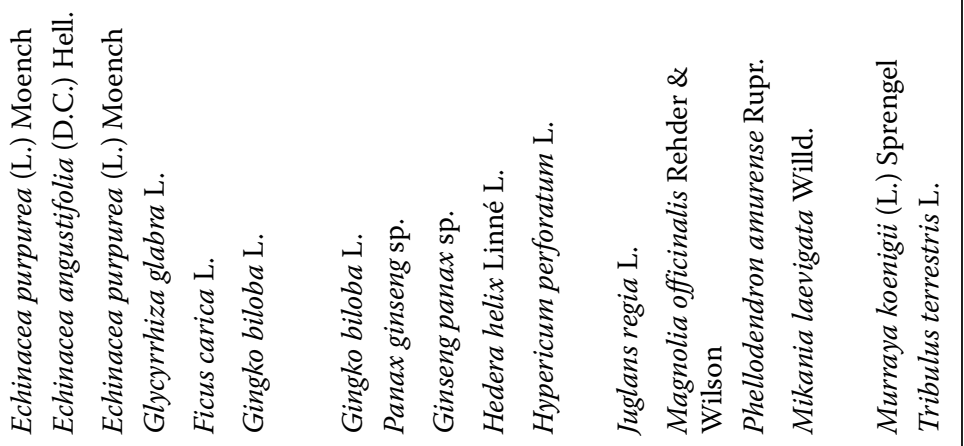




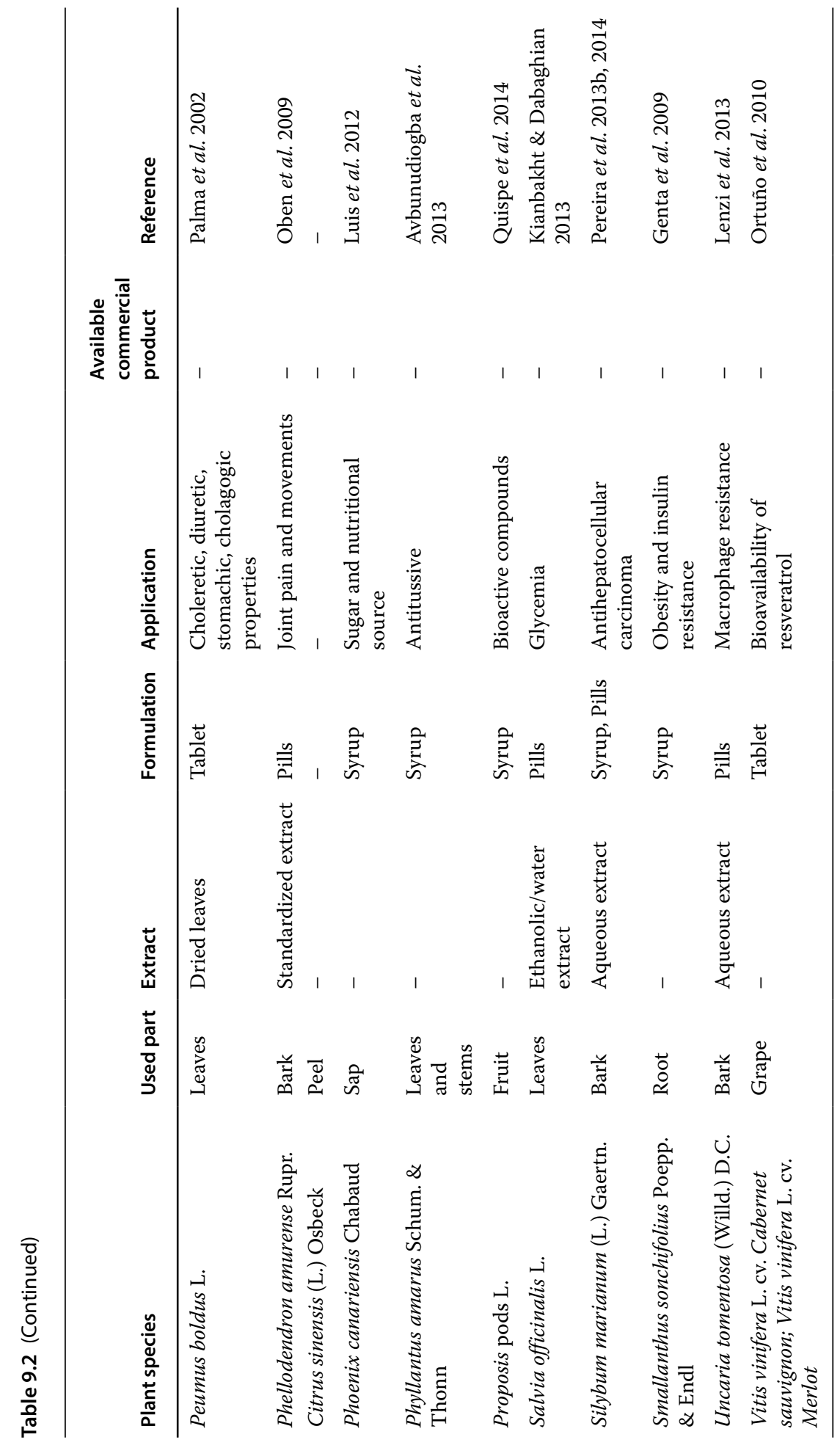


plants that are normally consumed as wild and that present some bioactive properties, allowing the development of nutraceutical formulations. In this chapter, we only discuss nutraceutical formulations in the form of dietetic supplements (capsules, tablets, syrup). A detailed description of microencapsulated nutraceuticals based on plants has been previously provided by Dias et al. (2015), where the most frequently used microencapsulation techniques and materials are described, and also the most common extracts and bioactive compounds, including also some applicability studies for the developed microcapsules (e.g. milk, cheese, yogurt, ice cream, pasta, meat, bread, and chewing gum enhanced with bioactive extracts of plant origin).

Currently, some trademarked plant-based nutraceuticals are used as adjuvants in several illness processes. For instance, Ciklavit ${ }^{\circledR}$ is a syrup which has effects again sickle cell anemia, prepared with an aqueous extract of Cajanus cajan L. seed, a plant found in semiarid tropical regions, commonly consumed in soups and rice dishes (Imaga et al. 2013). Xu et al. (2010) studied the effect of a commercial product, Eufortyn ${ }^{\circledR}$, that comprises chemical compounds including terclatrated coenzyme $\mathrm{Q}_{10}$ and creatine, but also an extract of Ginseng panax sp. roots, which has shown effects in the antiaging process of rats. The roots of Echinacea purpurea (L.) Moench and Glycyrrhiza glabra L. are the major constituents of a commercial tablet, Revitonil ${ }^{\oplus}$, used mainly for its immunological effects, while the leaves of Hedera helix L. are used in Prospon ${ }^{\bullet}$, marketed for cough symptoms (Stauss-Grabo et al. 2011; Wagner \& Jurcic 2002). Extramel ${ }^{\circ}$ consists of small pills of melon juice (Cucumis melo var. cantalupensis Naudin) used to treat stress and fatigue symptoms (Milesi et al. 2009), while 5-Loxin ${ }^{\odot}$ and Aflapin ${ }^{\odot}$ contain gum extract and gum extract plus oil, respectively, of Boswella serrata Triana \& Planch, being used for osteoarthritis (Sengupta et al. 2010).

The genus Echinacea is well known for its medicinal properties. Brinkeborn et al. (1989) reported the effects of pills (Echinaforce ${ }^{\odot}$ ) prepared from E. purpurea roots and leaves in the treatment of the common cold, while Dapas et al. (2014) studied the root syrup (Polinacea ${ }^{\oplus}$ ) obtained using E. angustifolia (D.C.) Hell. for its immunomodelatory effects. Berbenol ${ }^{\circ}$, a tablet formulation made from an extract of Berberis aristata D.C. and Silybum marianum (L.) Gaertn., taking advantage of the synergistic effects of both plants, is used for the treatment of glycemia and lipid value alterations in patients with type 2 diabetes (Pierro et al. 2013).

However, most of the formulations reported in the literature as nutraceuticals do not reach the market due to a lack of more in-depth studies, including clinical trials, or for legal or technical reasons. Lenoir et al. (1999) tested the effects of tablets containing three different concentrations of shoot tips from Hypericum perfuratum L. on symptoms in patients with mild to moderate depression. The bark of Phellodendron amurense Rupr., traditionally used in Chinese medicine, and the peel of Citrus sinensis (L.) Osbeck were inserted into pills in order to evaluate their beneficial effects in joint pain; both species contributed to weight loss in tested patients and also an improvement in their health status (Oben et al. 2009). The leaves of Murraya koenigii (L.) Sprengel and Tribulus terrestris L. are traditionally used in India for curry and to treat infertility and impotence, respectively. Sengupta et al. (2011) studied the effects of both plant pills in benign prostatic hyperplasia, obtaining satisfactory results.

Type 2 diabetes is increasing worldwide; moreover, the additional health problems related to this disease are also an important concern. Kianbakht and Dabaghian (2013) reported the effects of pills prepared from Salvia officinalis L. leaves in patients with 
type 2 diabetes and hyperlipidemia, describing good results in contrast to the placebo group, and without adverse side-effects. Furthermore, Hosseini et al. (2014) proved the effectiveness of pills obtained from Juglans regia L. leaves in patients with type 2 diabetes. Genta et al. (2009) studied humans given "yacon" syrup obtained from the roots of Smallanthus sonchifolius Poepp. \& Endl with a high fructooligosaccharide content, demonstrating beneficial health effects in insulin-resistant patients.

Age-related cognitive changes and dementia are also a worldwide concern. Gingko biloba L. leaves have been described as being able to affect some neurological properties. Bäurle et al. (2009) studied the effects of tablets made from the extract of this plant in mild cognitive impairment; the authors reported the nutraceutical as safe, effective, and acting as an adjuvant to patients who suffer from this illness. There is already on the market a product, $\mathrm{Memo}^{\circledR}$, prepared from G. biloba leaves and Panax ginseng sp. roots, used against mild cognitive impairment, by slowing the cognitive decline that occurs during the aging process (Yakoot et al. 2013). Cognitive wellbeing is also related to stress, depression, and fatigue, and the methods used to treat stress conditions range from a balanced nutritional plan to powerful drugs such as benzodiazepines. Relora ${ }^{\circ}$ is a pill formulation consisting of a blend of bark extracts of Magnolia officinalis Rehder \& Wilson and $P$. amurense standardized to honokiol and berberine, respectively, used in the treatment of stress and anxiety; the results achieved in a clinical trial performed by Talbott et al. (2013) showed that the combination of these two plants improved a variety of mood state parameters, lowering fatigue and increasing vigor.

Current stress-related diseases are a direct consequence of our modern lifestyle; the human organism produces reactive oxygen species, which are related to higher incidences of cardiovascular, brain, and immune system diseases (Carocho \& Ferreira 2013b). Therefore, nutraceutical formulations are also being studied for their antioxidant properties, such as the syrup obtained from the fruits of Ficus carica L. and Prosopis pods, both widely used in traditional cuisine to prepare desserts and sweets (Puoci et al. 2011; Quispe et al. 2014). Furthermore, the syrup and pills prepared from G. biloba leaves, known for their action against degenerative neurological diseases, as previously mentioned, but also for their action in the cardiovascular system and cerebral vascular activity, were studied for their antioxidant capacity, showing higher activity than the corresponding infusion and extract; this higher activity was attributed to the highest content in phenolic compounds (Pereira et al. 2013a). Pereira et al. (2013b, 2014) also tested different nutraceutical formulations (pills and syrup) prepared using Cynara scolymus L., Cochlospermum angolensis Welw., and S. marianum, known for their capacity to prevent oxidative stress and liver disease, in terms of antioxidant and antihepatocellular carcinoma activities; the synergistic effects between these nutraceuticals (mixtures) were also assessed, showing many advantages over individual components.

The bioavailability of nutraceutical formulations is also a hot research topic as metabolic reactions can decrease their bioactive properties. There are already some studies in this direction, such as the one conducted by Matthias et al. (2007) on liquid (alcoholic solution) and tablet formulations prepared with E. purpurea and E. angustifolia roots. Alkylamides, found in both species, were used as target compounds to evaluate the nutraceuticals' bioavailability; these compounds were rapidly and easily absorbed in both formulations. A similar study was performed with tablets prepared with red wine grape extracts made from Vitis vinifera L. cv. Cabernet sauvignon and Vitis vinifera 
L. cv. Merlot, in order to assess the bioavailability of resveratrol; however, in this case the bioavailability was higher in the natural matrix than in the nutraceutical formulation (Ortuño et al. 2010).

Nutraceuticals can also combine plant-based principles with other natural matrices such as mushrooms. A good example is ASHMI ${ }^{\mathrm{TM}}$, a pill formulation use in asthma treatment, containing the plants Sophora flavescens Aiton and glycyrrhiza uralensis Fisch. (root aqueous extracts) and the mushroom Ganoderma lucidum (Curtis) P. Karst. (fruiting body aqueous extracts) (Kelly-Pieper et al. 2009). Wong et al. (2004) also studied the effects of Coriolus versicolor (L.: Fr.) Quél. and Salvia miltiorrhiza Bunge pills (polysaccharides extract) on the improvement of cellular immunity in healthy subjects, which proved to be effective and without adverse effects.

\subsection{Wild Plant-Based Drugs}

\subsubsection{From the Bioactive Phytochemical to the Active Principle}

Plants have been used as medicine by humans for thousands of years, since their first use as teas, tinctures, poultices, etc. to the isolation of morphine from opium in the early nineteenth century. Since then, administration methods have changed drastically (Balunas \& Kinghorn 2005; Newman et al. 2000). Today, there are many sources of new bioactive compounds, including plants, bacteria, fungi, and marine organisms; in fact, from 1981 to $2002,61 \%$ of the 877 new small molecule chemical compounds were derived from natural products, and in specific therapeutic areas (antibacterial, antifungal, antiparasitic, and antiviral treatments), these compounds have provided $70 \%$ of total drugs (Cechinel-Filho 2012). There are six classes of compounds that result from botanical sources:

- bioactive compounds that are used directly as drugs, as in the case of digoxin, used for heart conditions

- bioactive compounds with structures that may act as lead compounds to more potent drugs, for instance, paclitaxel, a mitotic inhibitor used in cancer chemotherapy

- chemophores, which are cells that transduce energy, and may be converted into druggable compounds

- pure phytochemicals that can be used as markers to standardize crude plant material

- phytochemicals that can be used as pharmacological tools

- herbal extracts as botanical drugs or green tea extracts (Katiyar et al. 2012).

Although there are numerous classes of compounds and methods of obtaining them, the pharmaceutical industry faces unprecedented challenges, with fewer compounds being found, tested, and released to the public. Typically, after in vitro assays showing bioactivity of a specific compound, it may start preclinical studies on animal models followed by a "New Drug Application" addressed to the FDA (USA) and EFSA (EU). If approved, the human studies take place, divided into three phases with escalating numbers of participants to determine the toxicity, side-effects, and other effects not detectable in animal models. The ideal approval process of a new drug is hardly ever linear, and several drawbacks ensue, meaning that several years to some decades may elapse before a compound is marketed as a drug (FDA 2014; Paul et al. 2010). Compounds leading to hypothetical 
drugs must achieve suitable solubility and chemical stability, demonstrate effectiveness in animals (adequate pharmacological profile) and satisfactory bioavailability (with a good half-life), the interactions with cytochrome p450 (CYP450) must be clarified and finally, there must be no obvious toxicity (Cechinel-Filho 2012).

With the reduction of new compounds appearing as potential drugs, humans have once again turned to Nature in order to mitigate the relative void of combinatorial chemistry to find new compounds (Phillipson 2007). The quest for compounds in plants can be carried out in many ways.

- Random selection followed by chemical screening (simple tests that may lead to false positives and false negatives, rendering conclusions difficult to assess and the class of compounds responsible for the activity impossible to specify).

- Random selection followed by one or more biological assays (carried out in animals or in vitro assays that screen high volumes of plant species in order to find new drugs).

- Follow-up of biological activity reports (reports of plant extracts with interesting biological activity, which were not studied for their active principles).

- Follow-up of ethnomedical (traditional medicine) uses of plants - plants used in traditional systems like Ayurveda, Unani, Kampo, and traditional Chinese medicine which are not seen as credible by Western scientific methods and are harder to assess, but their undeniable results in many illnesses are impossible to overlook. Herbalism, folklore, and shamanism, which are also viewed with scepticism, are also considered due to their strong reliance on endemic plants.

- Use of databases (large literature sources systematically organized that allow correlation of ethnomedical practices with experimental biochemical and pharmacological activities or to identify plants with multiple effects) (Fabricant \& Farnsworth 2001).

To achieve the final compound, a large number of molecules must be extracted from the medicinal plant through various methods.

- Percolation, used for poorly soluble plants or when the price of the plant is relevant. The matrix is placed in a container with solvent flowing through it.

- Countercurrent extraction is obtained by moving solvent through the raw plant in countercurrent.

- Supercritical fluid extraction is carried out by placing the raw plant in a container and filling it with supercritical fluid until the pressure and temperature rise by a considerable amount. These conditions help the fluid to achieve a very high solubility capacity, extracting the compounds of interest.

- Microwave-assisted extraction relies on microwaves that extract compounds more selectively and rapidly while depending less on solvents.

- Maceration is the process of placing the raw plant in a container for different periods of time, while kinetic maceration uses the same process but the mixture is maintained under constant stirring.

- Turbo-extraction uses a cold solvent at high sheer forces, which leads to particle reduction, cell disintegration, and temperature increase.

- Decoctions and infusions rely on hot water as the extractor. Infusions are prepared by adding the plant to boiling water, and maintaining it for 5-10 minutes, while decoctions are prepared by adding the plant to cold water and heating it until it boils, maintaining it for 5-10 minutes. 
- Soxhlet extraction relies on cycles of extraction within a glass chamber in which the solvent boils and condenses back into contact with the plant. After filling the chamber it is unloaded into a glass recipient that is heated, evaporating the solvent, only to condense back into the chamber, in a cyclical way.

- Sublimation extraction sublimes the compounds of interest leaving behind impurities which then condense in another chamber.

- Steam distillation relies on steam to carry the compounds from the boiling mixture containing the plant which then condenses.

- Ultrasonic-assisted extraction is used to increase mass transfer between the plant material and a solution by inducing liquid circulation and turbulence (Cechinel-Filho 2012; Sarker \& Nahar 2012; Sticher 2008).

After extraction, the solutions have to be screened to determine their constituents and dereplication (which is the process that recognizes previously studied components that are not important for a screening of new ones) to then prepare for separation and isolation. To separate and isolate the mixtures into their constituents, several methods are used; HPLC is the simplest and can yield results in a short time without needing derivatization steps, although the results can be poor in resolution, and confusing. Ultra high-pressure liquid chromatography (UHPLC) is an improvement on HPLC by enhancing the resolution and throughput for rapid fingerprinting of crude extracts. Liquid chromatography coupled to a photo diode array (LC-PDA) detector is another add-on to a HPLC by allowing a view of the UV spectra, which is useful for detecting compounds with characteristic chromophores. HPLC-MS is HPLC that is coupled to a mass spectrometer, aiding detection, quantification, and identification by providing at the same time a chromatographic (retention times) and a mass spectrometric $(\mathrm{m} / \mathrm{z})$ dimension. HPLC-NMR is one of the strongest HPLC methods used to separate compounds. It has the advantage of not relying on commercial databases for spectral comparison, like HPLC-MS. HPLC-NMR provides structural information or even stereochemical information, as well as detection of any hydrogen-containing compounds. LC-SPE-NMR uses a solid-phase extraction coupled to a HPLC and finally a NMR detector, and allows the NMR detection after HPLC separation by either trapping the peaks on SPE or by HPLC microfractionation, drying, and reinjection of the concentrated peak in a microflow capillary LC-NMR probe. Microflow NMR and cryogenized probes are derivations of this technique (Cechinel-Filho 2012).

It is incontestable that medicinal plants provide unlimited opportunities for new drug discovery because of the unmatched availability of chemical diversity. Nevertheless, since bioactive phytochemicals occurring in plant materials consist of multicomponent mixtures, their extraction, separation, and isolation still create problems. In fact, extraction techniques can negatively affect the integrity of active principles, and practically all of them have to be purified by the combination of several chromatographic techniques or various other purification methods. Thus, it is expected that improvements in these methods will allow us to overcome some of the current limitations, as well as driving the development and introduction of new technologies.

\subsubsection{Common Formulations in Drugs from Plant Origin}

Drug development has evolved steadily since it first began as part of traditional medicine, and today more and more plant compounds are used as precursors, prototypes, and probes in drug production (Ramawat \& Mérillon 2008). Depicted in Table 9.3 are 


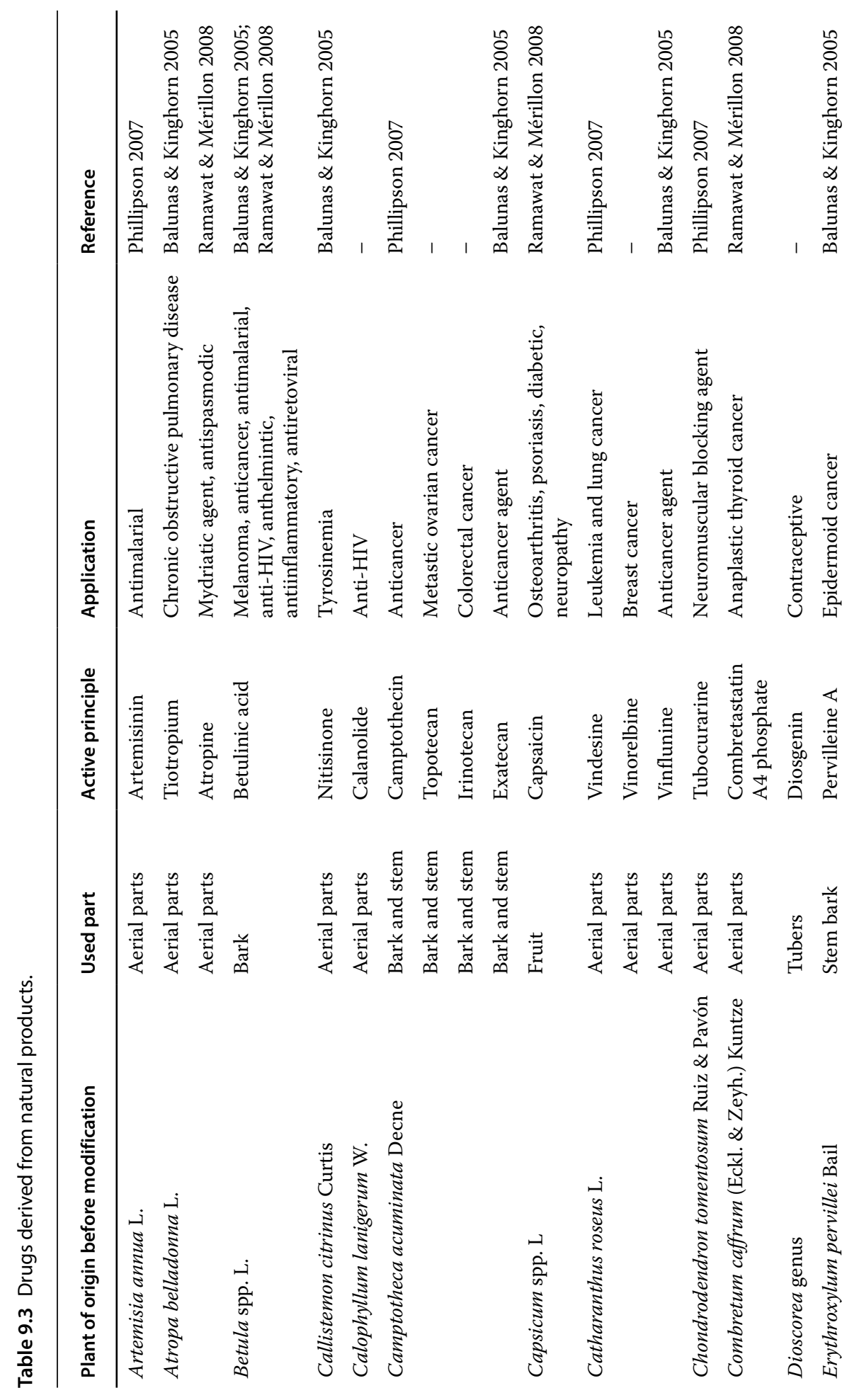



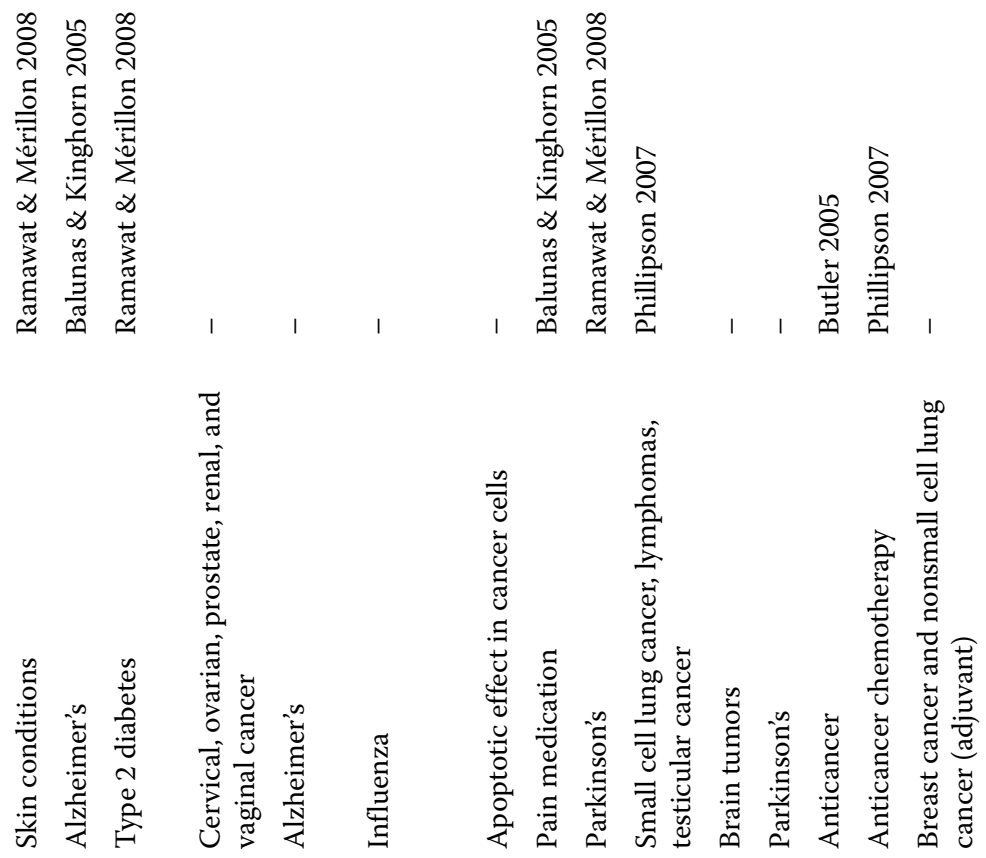

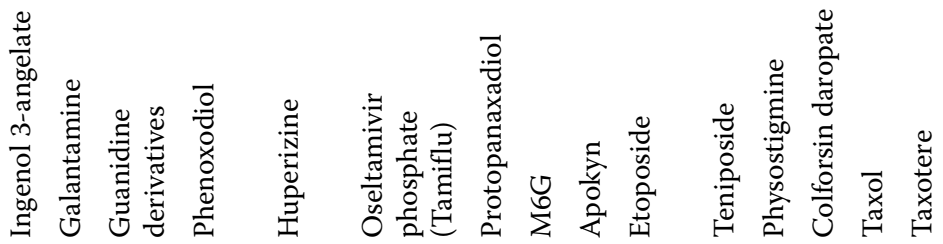

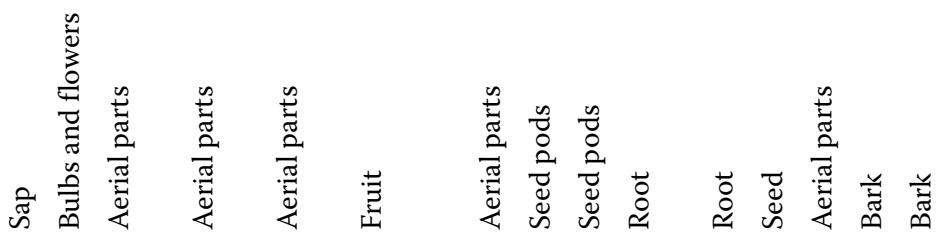

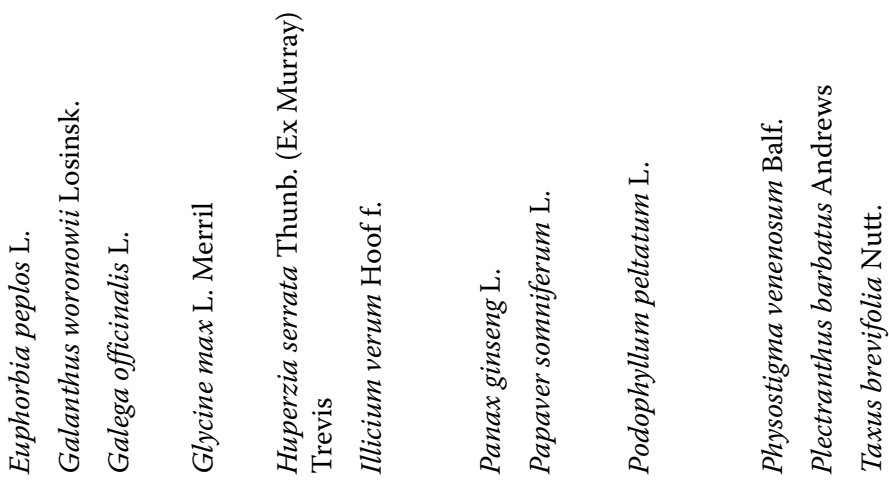


some of the most important drugs either developed using compounds derived from plants, or synthetic ones that were inspired by them, along with the plant from which they were first isolated and the illnesses they are used for. The recent change of attitude from big pharmaceutical companies, which are starting to look for natural compounds, has been a major tonic in the industry, helping to develop new drugs. The applications of natural compounds for human health are endless, and considering that currently only one-quarter of flowering plants is used, there is hope of finding treatments and solutions for many patients around the world (Lange 2004).

The WHO reports that over 21000 plant taxa are used for medicinal purposes, although this number does not include cosmetics, spirits, and aromas (FAO 2002; Lange 2004). Roughly $80 \%$ of developing countries depend on plant-based drugs, although the WHO suggests that in the near future a similar percentage of the entire world population will depend on them. Furthermore, 30\% of the drugs sold worldwide contain products derived from plants (FAO 2005).

Of the global trade in medicinal plants, it is hard to know how much is represented by wild or cultivated ones. Although the pharmaceutical industry has isolated a large number of bioactive compounds from wild plants (edible and medicinal), there are considerable disadvantages in harvesting wild medicinal plants rather than cultivating them for industrial drug development. The pharmaceutical industry mainly uses cultivated plants as primary material, despite the expensive domestication and cultivation process, in order to obtain a standard and well-known source of the active principle, in the necessary amounts for industrial-level processing. Moreover, there are some disadvantages related to wild plant gathering, including uncontrolled harvest that leads to extinction of the plant and erosion of the ecosystem. Other problems include poor knowledge about the biology of the plants, little or no inventory, ownership conflicts of the harvest zones, and scarce income due to overharvesting. Cultivation in small farms and households or in large and extensive production facilities could be an alternative, although the disadvantages are still great, due to the large investments needed, the reduction of incentive to conserve native ecosystems, devaluation of wild plants, reduction of genetic diversity and the risk of the introduced plant becoming an invasive species (FAO 2002).

\subsubsection{Wild Plant-Based Drugs for Different Therapeutic Targets}

Wild plant-based drugs are everywhere; the definition of a drug is quite vague, encompassing all "chemical substances used in the treatment, cure, prevention, or diagnosis of disease or used to otherwise enhance physical or mental well-being." In this way, all molecules used by any type of medicine, modern or traditional, could be classed as drugs. To narrow down the results, only drugs used and approved in Western modern medicine are considered here, otherwise the list would be endless, although alternative medicines are quite well documented (Ahmad et al. 2006; Hawkins 2008; Osbourn \& Lanzotti 2009; Trivedi 2009).

Medicinal plants represent $25 \%$ of prescription drugs in modern medicine. Of the 3000 plants traded for medicinal purposes, only 900 are cultivated, which means that $70-80 \%$ of the whole market depends on wild collection (Hawkins 2008). The conservation of habitats of these plants is the responsibility of the Convention on International Trade in Endangered Species of Wild Fauna and Flora (CITES), which 
is the most important source of information on wild medicinal plants in use. Galanthus spp. L., an herbaceous plant endemic to the northern hemisphere, is the source of galanthamine, an approved drug used against Alzheimer's disease (Heinrich \& Teoh 2004). Taxus brevifolia Nutt., the conifer that is the source of the anticancer agent $\mathrm{Taxol}^{\circ}$, also known as paclitaxel, is another success story of the medicinal power of plants, although it has endangered some cultivars of the tree. The alkaloid colchicine, derived from Colchicum autumnale L. corms, is used for the treatment of gout, under the name Colcrys (Romano 2013). The treatment of cardiac diseases also depends on compounds derived from wild medicinal plants, including digoxin, a cardiac glycoside extracted from the herb Digitalis lanata Ehrh. It is also marketed under the names Lanoxin ${ }^{\odot}$, Lanoxicaps ${ }^{\oplus}$, Cardoxin $^{\circledR}$ and Digitek ${ }^{\oplus}$, among others (Hawkins 2008). The cinchona tree, Cinchona officinalis L., endemic to South America, is a natural source of quinine, a known antimalarial alkaloid that is used against this disease in modern medicine. There are reports of other uses of this molecule, which have recently been investigated (Christoforidis 2014). Camptotheca acuminata Decne is a tree native to China and Tibet which is rich in an alkaloid called camptothecin, used as an anticancer agent (Gaur et al. 2014). These examples illustrate some of the illnesses that can be cured or attenuated with wild plant compounds.

The endless combination of compounds found in nature that may have application in medicine provides hope for treatments of illnesses that have not yet been controlled or cured. The search to find new compounds continues at a steady pace and technology keeps lending precious help to this quest. Wild medicinal plants are today still as valuable as they were in the pre-modern medicine era. However, the pursuit of bioactive compounds should never overlook the habitats and wellbeing of the species. Research should continue to try and cultivate the plants that are not yet fit to be intensively grown, therefore reducing dependency on wild plants. But while there is no alternative, mankind should harvest them from nature, but always ensuring their continuity for generations to come.

\subsection{Conclusion}

Functional foods and nutraceuticals have been reported as one of the top trends of today's food industry. Apart from the naturally occurring functional foods, the development of new functional foods, nutraceuticals, and drugs based on plants is an active and very promising area of research, indispensable for the substantiation of health claims and benefits. The characterization of plant ingredients by advanced technologies, standardization of human clinical trials, and the use of emerging methodologies are crucial strategies for the development of new functional products and drugs. Additionally, the degree of acceptance and awareness of functional foods and nutraceuticals by consumers, the association between manufacturers and academic researchers, and the effects of new regulations for nutrition and health claims are crucial factors for future market evolution. Despite all the potential of these products to prevent diseases and promote human health, health professionals, nutritionists, and regulatory toxicologists should work together to plan appropriate regulation to provide the ultimate health and therapeutic benefit to humans. 
However, due to the rising demand for plant-based functional foods, nutraceuticals, and drugs in higher quantities to promote health, longevity, and quality of life, wild harvested medicinal plants are taking on an increasing role and many of them have become endangered due to irresponsible collection, associated with economic interests. Therefore, the cultivation of these species is an alternative that needs to be taken into account. Furthermore, the next phase of market growth depends on valid scientific research for new product technologies, patents, more effective branding, and trademark strategies in product manufacture and international regulatory compliance.

\section{References}

Adão, C. R., Silva, B. P. \& Parente, J. P. (2011) A new steroidal saponin with antiinflammatory and antiulcerogenic properties from the bulbs of Allium ampeloprasum var. porrum. Fitoterapia 82, 1175-1180.

Ahmad, I., Aqil, F., Owais, M., eds. (2006) Modern Phytomedicine: Turning Plants into Drugs. Weinheim: Wiley-Vch.

Amagase, H. \& Farnsworth, N. R. (2011) A review of botanical characteristics, phytochemistry, clinical relevance in efficacy and safety of Lycium barbarum fruit (Goji). Food Research International 44, 1702-1717.

Andlauer, W. \& Furst, P. (2002) Nutraceuticals: a piece of history, present status and outlook. Food Research International 35, 171-176.

Annunziata, A. \& Vecchio, R. (2011) Functional foods development in the European market: a consumer perspective. Journal of Functional Foods 3, 223-228.

Ashwell, M. (2003) Concepts of Functional Foods. ILSI Europe Concise Monograph Series. Brussels: ILSI Europe.

Avbunudiogba, J. A., Alalor, C. A., Builders, P. F., et al. (2013) Development and evaluation of liquid oral phytoformulation of Phyllanthus amarus. Journal of Pharmacy Research 6, 908-912.

Bagchi, D., ed. (2014) Nutraceutical and Functional Food Regulations in the United States and Around the World, 2nd edn. Houston: Academic Press.

Balunas, M. J. \& Kinghorn, A. D. (2005) Drug discovery from medicinal plants. Life Sciences 78, 431-441.

Barolo, M. I., Mostacero, N. R. \& López, S. N. (2014) Ficus carica L. (Moraceae): an ancient source of food and health. Food Chemistry 164, 119-127.

Barros, L., Carvalho, A. M., Sa Morais, J., et al. (2010) Strawberry-tree, blackthorn and rose fruits: detailed characterisation in nutrients and phytochemicals with antioxidant properties. Food Chemistry 120, 247-254.

Barros, L., Cabrita, L., Vilas Boas, M., et al. (2011a) Chemical, biochemical and electrochemical assays to evaluate phytochemicals and antioxidant activity of wild plants. Food Chemistry 127, 1600-1608.

Barros, L., Dueñas, M., Ferreira, I. C. F. R., et al. (2011b) Use of HPLC-DAD-ESI/MS to profile phenolic compounds in edible wild greens from Portugal. Food Chemistry 127, 169-173.

Bäurle, P., Suter, A. \& Wormstall, H. (2009) Safety and effectiveness of a traditional ginkgo fresh plant extract - results from a clinical trial. Forschende Komplementarmedizin 16, 156-161. 
Bech-Larsen, T. \& Scholderer, J. (2007) Functional foods in Europe: consumer research, market experiences and regulatory aspects. Trends in Food Science and Technology 18, 231-234.

Bernal, J., Mendiola, J. A., Ibáñez, E., et al. (2011) Advanced analysis of nutraceuticals. Journal of Pharmaceutical and Biomedical Analysis 55, 758-774.

Betoret, E., Betoret, N., Vidal, D. et al. (2011) Functional foods development: trends and technologies. Trends in Food Science and Technology 22, 498-508.

Bhardwaj, Y. R., Pareek, A., Jain, V., et al. (2014) Chemical delivery systems and soft drugs: retrometabolic approaches to drug design. Saudi Pharmaceutical Journal 22, 290-302.

Bhoopat, L., Srichairatanakool, S., Kanjanapothi, D., et al. (2011) Hepatoprotective effects of lychee (Litchi chinensis Sonn.): a combination of antioxidant and anti-apoptotic activities. Journal of Ethnopharmacology 136, 55-66.

Bowen-Forbes, C. S., Zhang, Y. \& Nair, M. G. (2010) Anthocyanin content, antioxidant, anti-inflammatory and anticancer properties of blackberry and raspberry fruits. Journal of Food Composition and Analysis 23, 554-560.

Braithwaite, M. C., Tyagi, C., Tomar, L. K., et al. (2014) Nutraceutical-based therapeutics and formulation strategies augmenting their efficiency to complement modern medicine: an overview. Journal of Functional Foods 6, 82-99.

Brinkeborn, R. M., Shah, D. V. \& Degenring F. H. (1989) Echinaforce ${ }^{\bullet}$ and other Echinacea fresh plant preparations in the treatment of the common cold. A randomized, placebo controlled, double-blind clinical trial. Phytomedicine 6, 1-5.

Butler, M. S. (2005) Natural products to drugs: natural product derived compounds in clinical trials. Natural Products Reports 22, 162-195.

Byrne, D. (2003) Health nutrition and labeling. Food Science and Technology 17, 26-28.

Caleja, C., Barros, L. Antonio, A. L., et al. (2015) Foeniculum vulgare Mill. as natural conservation enhancer and health promoter by incorporation in cottage cheese. Journal of Functional Foods 12, 428-438.

Carocho, M. \& Ferreira, I. C. F. R. (2013a) The role of phenolic compounds in the fight against cancer - a review. Anti-Cancer Agents in Medicinal Chemistry 13, 1236-1238.

Carocho, M. \& Ferreira, I. C. F. R. (2013b) A review on antioxidants, prooxidants and related controversy: natural and synthetic compounds, screening and analysis methodologies and future perspectives. Food and Chemical Toxicology 51, 15-25.

Carocho, M., Barreira, J. C. M., Antonio, A. L., et al. (2015a) The incorporation of plant materials in "Serra da Estrela" cheese improves antioxidant activity without changing the fatty acid profile and visual appearance. European Journal of Lipid Science and Technology 117, 1607-1614.

Carocho, M., Barreira, J. C. M., Barros, L., et al. (2015b) Traditional pastry with chestnut flowers as natural ingredients: an approach of the effects on nutritional value and chemical composition. Journal of Food Composition and Analysis 44, 93-101.

Cechinel-Filho, V., ed. (2012) Plant Bioactivities and Drug Discovery: Principle, Practice, and Perspectives. New Jersey: John Wiley.

Cerqueira, M. A., Pinheiro, A. C., Silva, H. D., et al. (2014) Design of bio-nanosystems for oral delivery of functional compounds. Food Engineering Reviews 6, 1-19.

Chen, L., Remondetto, G. E. \& Subirade, M. (2006) Food protein-based materials as nutraceutical delivery systems. Trends in Food Science and Technology 17, 272-283.

Christoforidis, J. (2014) Quinine. Reference module in biomedical sciences. In: P. Wexler, ed. Encyclopedia of Toxicology, 3rd edn. Philadelphia: Elsevier, pp 19-22. 
Coppens, P., Silva, M. F. \& Pettman, S. (2006) European regulations on nutraceuticals, dietary supplements and functional foods: a framework based on safety. Toxicology 221, 59-74.

Costa, A. G. V., Garcia-Diaz, D. F., Jimenez, P. et al. (2013) Bioactive compounds and health benefits of exotic tropical red-black berries. Journal of Functional Foods 5, 539-549.

Dapas, B., Dall'Acqua, S., Bullac, R., et al. (2014) Immunomodulation mediated by a herbal syrup containing a standardized Echinacea root extract: a pilot study in healthy human subjects on cytokine gene expression. Phytomedicine 21, 1406-1410.

DeFelice, S. L. (1992) The nutraceutical initiative: a recommendation for U.S. economic and regulatory reforms. Genetic Engineering News 12, 13-15.

Delva, L. \& Goodrich-Schneider, R. (2013) Antioxidant activity and antimicrobial properties of phenolic extracts from acerola (Malpighia emarginata DC) fruit. International Journal of Food Science and Technology 48, 1048-1056.

Dias, F. M., Leffa, D. D., Daumann, F., et al. (2014) Acerola (Malpighia emarginata DC.) juice intake protects against alterations to proteins involved in inflammatory and lipolysis pathways in the adipose tissue of obese mice fed a cafeteria diet. Lipids in Health and Disease 13, 1-9.

Dias, M. I., Ferreira, I. C. F. R. \& Barreiro, M. F. (2015) Microencapsulation of bioactives for food applications. Food and Function 6, 1035-1052.

Diplock, A., Aggett, P. J., Ashwell, M., et al. (1999) Scientific concepts of functional foods in Europe: consensus document. British Journal of Nutrition 81, 1-27.

Espín, J. C., García-Conesa, M. \& Tomás-Barberán, F. (2007) Nutraceuticals: facts and fiction. Phytochemistry 68, 2986-3008.

Ezhilarisi, P. N., Karthik, P., Chhanwal, N., et al. (2013) Nanoencapsulation techniques for food bioactive components: a review. Food Bioprocess Technology 6, 628-647.

Fabricant, D. S. \& Farnsworth, N. R. (2001) The value of plants used in traditional medicine for drug discovery. Environmental Health Perspectives 109, 69-75.

FAO (2002) Impact of Cultivation and Gathering of Medicinal Plants on Biodiversity: Global Trends and Issues. Available at: ftp://ftp.fao.org/docrep/fao/005/aa010e/ AA010E00.pdf (accessed 27 June 2016).

FAO (2005) Trade in Medicinal Plants. Raw Materials, Tropical and Horticultural Products Service Commodities and Trade Division. Available at: ftp://ftp.fao.org/docrep/fao/008/ af285e/af285e00.pdf (accessed 27 June 2016).

FDA (2014) FDA's Drug Review Process: Continued. Available at: www.fda.gov/Drugs/ ResourcesForYou/Consumers/ucm289601.htm (accessed 27 June 2016).

Flores, G., Wu, S. B., Negrin, A., et al. (2015) Chemical composition and antioxidant activity of seven cultivars of guava (Psidium guajava) fruits. Food Chemistry 170, 327-335.

Fracassetti, D., Costa, C., Moulay, L., et al. (2013) Ellagic acid derivatives, ellagitannins, proanthocyanidins and other phenolics, vitamin $\mathrm{C}$ and antioxidant capacity of two powder products from camu-camu fruit (Myrciaria dubia). Food Chemistry 139, 578-588.

García-Herrera, P., Morales, P., Fernández-Ruiz, V., et al. (2014) Nutrients, phytochemicals and antioxidant activity in wild populations of Allium ampeloprasum L., a valuable underutilized vegetable. Food Research International 62, 272-279.

Garcia-Rios, A., Delgado-Lista, J., Alcala-Diaz, J. F., et al. (2013) Nutraceuticals and coronary heart disease. Current Opinion in Cardiology 28, 475-482. 
Gaur, S., Wang, Y., Kretzner, L., et al. (2014) Pharmacodynamic and pharmacogenomics study of the nanoparticle conjugate of camptothecin CRLX10 for the treatment of cancer. Nanomedicine: Nanotechnology, Biology, and Medicine 10, 1477-1486.

Genta, S., Cabrera, W., Habib, N., et al. (2009) Yacon syrup: beneficial effects on obesity and insulin resistance in humans. Clinical Nutrition 28, 182-187.

Giordano, P., Scicchitano, P., Locorotondo, M., et al. (2012) Carotenoids and cardiovascular risk. Current Pharmaceutical Design 18, 5577-5589.

Graça, C., Freitas, C. S., Baggio, C.H., et al. (2007) Mikania laevigata syrup does not induce side effects on reproductive system of male Wistar rats. Journal of Ethnopharmacology 111, 29-32.

Granato, D., Branco, G. F. \& Nazzaro, F. (2010) Functional foods and nondairy probiotic food development: trends, concepts and products. Comprehensive Reviews in Food Science and Food Safety 9, 292-302.

Grivetti, L. E. \& Ogle, B. M. (2000) Value of traditional foods in meeting macro- and micronutrient needs: the wild plant connection. Nutrition Research Reviews 13, 31-46.

Groot, R. S., Wilson, M. A. \& Boumans, R. M. J. (2002) A typology for the classification, description and valuation of ecosystem functions, goods and services. Ecological Economics 41, 393-408.

Guimarães, R., Barros, L., Dueñas, M., et al. (2013) Characterisation of phenolic compounds in wild fruits from Northeastern Portugal. Food Chemistry 141, 3721-3730.

Guimarães, R., Barros, L., Calhelha, R. C., et al. (2014) Bioactivity of different enriched phenolic extracts of wild fruits from Northeastern Portugal: a comparative study. Plant Foods for Human Nutrition 69, 37-42.

Gulati, O. P. \& Ottaway, P. B. (2006) Legislation relating to nutraceuticals in the European Union with a particular focus on botanical-sourced products. Toxicology 221, 75-87.

Gutierrez-Orozco, F. \& Failla, M. L. (2013) Biological activities and bioavailability of mangosteen xanthones: a critical review of the current evidence. Nutrients $\mathbf{5}$, 3163-3183.

Hasler, C. M. (2000) The changing face of functional foods. Journal of the American College of Nutrition 19, 499-506.

Hasler, C. M. (2002) Functional foods: benefits, concerns and challenges - a position paper from the American Council on Science and Health. Journal of Nutrition 132, 3772-3781.

Hawkins, B., ed. (2008) Plants for Life: Medicinal Plant Conservation and Botanic Gardens. London: Botanic Gardens Conservation International.

Heinrich, M. \& Teoh, H. L. (2004) Galanthamine from snowdrop - the development of a modern drug against Alzheimer's disease from local Caucasian knowledge. Journal of Ethnopharmacology 92, 147-162.

Heywood, V. H. (2011) Ethnopharmacology, food production, nutrition and biodiversity conservation: towards a sustainable future for indigenous peoples. Journal of Ethnopharmacology 137, 1-15.

Hosseini, S., Jamshidi, L., Mehrzadi, S., et al. (2014) Effects of Juglans regia L. leaf extract on hyperglycemia and lipid profiles in type two diabetic patients: a randomized double-blind, placebo-controlled clinical trial. Journal of Ethnopharmacology 152, 451-456.

Howlett, J. (2008) Functional Foods: From Science to Health and Claims. Brussels: ILSI Europe.

Huang, G. J., Wang, B. S., Lin, W. C., et al. (2012) Antioxidant and anti-inflammatory properties of longan (Dimocarpus longan Lour.) pericarp. Evidence-Based Complementary and Alternative Medicine 2012, 1-10. 
Huang, Q., Yu, H. \& Ru, Q. (2010b) Bioavailability and delivery of nutraceuticals using nanotechnology. Journal of Food Science 75, 50-57.

Huang, W. Y., Cai, Y. Z., Corke, H., et al. (2010a) Survey of antioxidant capacity and nutritional quality of selected edible and medicinal fruit plants in Hong Kong. Journal of Food Composition and Analysis 23, 510-517.

Imaga, N. A., Chukwu, C. E., Blankson, A., et al. (2013) Biochemical assessment of Ciklavit $^{\oplus}$, a nutraceutical used in sickle cell anemia management. Journal of Herbal Medicine 3, 137-148.

Ismail, T., Sestili, P. \& Akhtar, S. (2012) Pomegranate peel and fruit extracts: a review of potential anti-inflammatory and anti-infective effects. Journal of Ethnopharmacology 143, 397-405.

Izzo, R., Simone, G., Giudice, R., et al. (2010) Effects of nutraceuticals on prevalence of metabolic syndrome and on calculated Framingham risk score in individuals with dyslipidaemia. Journal of Hypertension 28, 1482-1487.

Janaswamy, S. \& Youngren, S. R. (2012) Hydrocolloid-based nutraceutical delivery systems. Food and Function 3, 503-507.

Kang, J., Xie, C., Li, Z., et al. (2011) Flavonoids from acai (Euterpe oleracea Mart.) pulp and their antioxidant and anti-inflammatory activities. Food Chemistry 128, 152-157.

Katiyar, C., Gupta, A., Kanjilal, S., et al. (2012) Drug discovery from plant sources: an integrated approach. AYU 33, 10-19.

Kelly-Pieper, K., Patil, S. P., Busse, P., et al. (2009) Safety and tolerability of an antiasthma herbal formula (ASHMI ${ }^{\mathrm{TM}}$ ) in adult subjects with asthma: a randomized, double-blinded, placebo-controlled, dose-escalation phase I study. Journal of Alternative and Complementary Medicine 15, 735-743.

Khoo, C. \& Falk, M. (2014) Cranberry polyphenols: effects on cardiovascular risk factors. In: R. R. Watson, V. R. Preedy \& S. Zibadi, eds. Polyphenols in Human Health and Disease. San Diego: Academic Press, pp 1049-1065.

Kianbakht, S. \& Dabaghian, F. H. (2013) Improved glycemic control and lipid profile in hyperlipidemic type 2 diabetic patients consuming Salvia officinalis L. leaf extract: a randomized placebo controlled clinical trial. Complementary Therapies in Medicine 21, 441-446.

Kim, J., Lee, K. W. \& Lee, H. J. (2011) Cocoa (Theobroma cacao) seeds and phytochemicals in human health. In: V. R. Preedy, R. R. Watson \& V. B. Patel, eds. Nuts and Seeds in Health and Disease Prevention. Philadelphia: Elsevier, pp 351-360.

Kwak, N. S. \& Jukes, D. J. (2001) Functional foods. Part 2: The impact of current regulatory terminology. Food Control 12, 109-117.

Lai, T. N. H., Andre, C., Rogez, H., et al. (2015) Nutritional composition and antioxidant properties of the sim fruit (Rhodomyrtus tomentosa). Food Chemistry 168, 410-416.

Lange, D. (2004) Medicinal and aromatic plants: trade, production, and management of botanical resources. Acta Horticulturae 629, 177-197.

Leite, A. V., Malta, L. G., Riccio, M. F., et al. (2011) Antioxidant potential of rat plasma by administration of freeze-dried jaboticaba peel (Myrciaria jaboticaba Vell Berg). Journal of Agricultural and Food Chemistry 59, 2277-2283.

Lenoir, S., Degenring, F. H. \& Saller, R. (1999) A double-blind randomised trial to investigate three different concentrations of a standardised fresh plant extract obtained from the shoot tips of Hypericum perforatum L. Phytomedicine 6, 141-146. 
Lenzi, R. M., Campestrini, L. H., Okumura, L. M., et al. (2013) Effects of aqueous fractions of Uncaria tomentosa (Willd.) D.C.on macrophage modulatory activities. Food Research International 53, 767-779.

Li, A. N., Li, S., Li, H. B., et al. (2014a) Total phenolic contents and antioxidant capacities of 51 edible and wild flowers. Journal of Functional Foods 6, 319-330.

Li, X., Zhao, J., Yang, M., et al. (2014c) Physalins and withanolides from the fruits of Physalis alkekengi L. var. franchetii (Mast.) Makino and the inhibitory activities against human tumor cells. Phytochemistry Letters 10, 95-100.

Li, Y., Ahmad, A., Kong, D., et al. (2014b) Recent progress on nutraceutical research in prostate cancer. Cancer and Metastasis Review 33, 629-640.

Liu, Y., Singh, D. \& Nair, M. G. (2012) Pods of Khejri (Prosopis cineraria) consumed as a vegetable showed functional food properties. Journal of Functional Foods 4, 116-121.

Luis, G., Rubio, C., Gutiérrez, A. J., et al. (2012) Palm tree syrup: nutritional composition of a natural edulcorant. Nutrición Hospitalaria 27, 548-552.

Lv, Q., Si, M., Yan, Y., et al. (2014) Effects of phenolic-rich litchi (Litchi chinensis Sonn.) pulp extracts on glucose consumption in human HepG2 cells. Journal of Functional Foods 7, 621-629.

Madhavi, D. L., Bomser, J., Smith, M. A. L., et al. (1998) Isolation of bioactive constituents from Vaccinium myrtillus (bilberry) fruits and cell cultures. Plant Science 131, 95-103.

Malafaia, C. R. A., Silva, B. P., Tinoco, L. W., et al. (2015) Structural characterization and gastroprotective property of a novel glucofructan from Allium ampeloprasum var. porrum. Carbohydrate Research 402, 44-49.

Manchali, S., Murthy, K. N. C. \& Patil, B. S. (2012) Crucial facts about health benefits of popular cruciferous vegetables. Journal of Functional Foods 4, 94-106.

Mannarino, M. R., Ministrini, S. \& Pirro, M. (2014) Nutraceuticals for the treatment of hypercholesterolemia. European Journal of Internal Medicine 25, 592-599.

Martins, A., Barros, L., Carvalho, A. M., et al. (2014) Phenolic extracts of Rubus ulmifolius Schott flowers: characterization, microencapsulation and incorporation into yogurts as nutraceutical sources. Food and Function 5, 1091-1100.

Martins, D., Barros, L., Carvalho, A. M., et al. (2011) Nutritional and in vitro antioxidant properties of edible wild greens in Iberian Peninsula traditional diet. Food Chemistry 125, 488-494.

Matthias, A., Addison, R. S., Agnew, L. L., et al. (2007) Comparison of Echinacea alkylamide pharmacokinetics between liquid and tablet preparations. Phytomedicine 14, 587-590.

McAlindon, T.E. (2006) Nutraceuticals: do they work and when should we use them? Clinical Rheumatology 20, 99-115.

McCook-Russell, K. P., Nair, M. G., Facey, P. C., et al. (2012) Nutritional and nutraceutical comparison of Jamaican Psidium cattleianum (strawberry guava) and Psidium guajava (common guava) fruits. Food Chemistry 134, 1069-1073.

McNamara, S. H. (1997) Dietary supplement legislation enhances opportunities to market nutraceutical-type products. Journal of Nutraceuticals, Functional and Medical Foods 1, 47-59.

Mezadri, T., Villaño, D., Fernández-Pachón, M. S., et al. (2008) Antioxidant compounds and antioxidant activity in acerola (Malpighia emarginata DC.) fruits and derivatives. Journal of Food Composition and Analysis 21, 282-290. 
Milesi, M., Lacan, D., Brosse, H., et al. (2009) Effect of an oral supplementation with a proprietary melon juice concentrate $\left(\right.$ Extramel $\left.^{\circ}\right)$ on stress and fatigue in healthy people: a pilot, double-blind, placebo-controlled clinical trial. Nutrition Journal 8, 1-7.

Milner, J. A. (2000) Functional foods: the US perspective. American Journal of Clinical Nutrition, 71, 1654-1659.

MMWR (1999) Achievements in public health, 1900-1999: safer and healthier foods. Morbidity and Mortality Weekly Report, 48, 905-913.

Mojani, M. S., Ghasemzadeh, A., Rahmat, A., et al. (2014) Assessment of bioactive compounds, nutritional composition and antioxidant activity of Malaysian young ginger (Zingiber officinale Roscoe). International Food Research Journal 21, 1931-1935.

Morales, P., Carvalho, A. M., Sánchez-Mata, M. C., et al. (2012) Tocopherol composition and antioxidant activity of Spanish wild vegetables. Genetic Resources and Crop Evolution 59, 851-863.

Najda, A., Dyduch-Siemińska, M., Dyduch, J., et al. (2014) Comparative analysis of secondary metabolites contents in Fragaria vesca L. fruits. Annals of Agricultural and Environmental Medicine 21, 339-343.

Newman, D. J., Cragg, G. M. \& Snader, K. M. (2000) The influence of natural products upon drug discovery. Natural Product Reports 17, 215-234.

Ninfali, P. \& Angelino, D. (2013) Nutritional and functional potential of Beta vulgaris cicla and rubra. Fitoterapia 89, 188-199.

Nöthlings, U., Murphy, S. P., Wilkens, L. R., et al. (2007) Flavonols and pancreatic cancer risk - the multiethnic cohort study. American Journal of Epidemiology 166, 924-931.

Oben, J., Enonchong, E., Kothari, S., et al. (2009) Phellodendron and Citrus extracts benefit joint health in osteoarthritis patients: a pilot, double-blind, placebo-controlled study. Nutrition Journal 8, 1-9.

Ohama, H., Ikeda, H. \& Moriyama, H. (2006) Health foods and foods with health claims in Japan. Toxicology 221, 95-111.

Ortuño, J., Covas, M. I., Farre, M., et al. (2010) Matrix effects on the bioavailability of resveratrol in humans. Food Chemistry 120, 1123-1130.

Osbourn, A. E. \& Lanzotti, V., eds. (2009) Plant-Derived Natural Products: Synthesis, Function and Application. Berlin: Springer Science + Business Media, LLC.

Palma, S., Luján, C., Llabot, J. M., et al. (2002) Design of Peumus boldus tablets by direct compression using a novel dry plant extract. International Journal of Pharmaceutics 233, 191-198.

Pardo de Santayana, M., Tardío, J., Blanco, E., et al. (2007) Traditional knowledge of wild edible plants used in the northwest of the Iberian Peninsula (Spain and Portugal): a comparative study. Journal of Ethnobiology and Ethnomedicine 3, 1-11.

Paul, S. M., Mytelka, D. S., Dunwiddie, C. T., et al. (2010) How to improve R\&D productivity: the pharmaceutical industry's grand challenge. Nature Reviews $\mathbf{9}$, 203-214.

Pedraza-Chaverri, J., Cárdenas-Rodríguez, N., Orozco-Ibarra, M., et al. (2008) Medicinal properties of mangosteen (Garcinia mangostana). Food and Chemical Toxicology 46, 3227-3239.

Peng, K., Yang, L., Zhao, S., et al. (2013) Chemical constituents from the fruit of Gardenia jasminoides and their inhibitory effects on nitric oxide production. Bioorganic and Medicinal Chemistry Letters 23, 1127-1131. 
Pereira, C., Barros, L., Carvalho, A. M., et al. (2011) Nutritional composition and bioactive properties of commonly consumed wild greens: potential sources for new trends in modern diets. Food Research International 44, 2634-2640.

Pereira, C., Calhelha, R. C., Barros, L., et al. (2013b) Antioxidant properties, antihepatocellular carcinoma activity and hepatotoxicity of artichoke, milkthistle and borututu. Industrial Crops Production 49, 61-65.

Pereira, C., Calhelha, R. C., Barros, L., et al. (2014) Synergisms in antioxidant and antihepatocellular carcinoma activities of artichoke, milk thistle and borututu syrups. Industrial Crops and Products 52, 709-713.

Pereira, E., Barros, L. \& Ferreira, I. C. F. R. (2013a) Chemical characterization of Ginkgo biloba L. and antioxidant properties of its extracts and dietary supplements. Industrial Crops and Products 51, 244-248.

Phillipson, J. D. (2007) Phytochemistry and pharmacognosy. Phytochemistry 68, 2960-2972.

Pierro, F. D., Putignano, P., Villanova, N., et al. (2013) Preliminary study about the possible glycemic clinical advantage in using a fixed combination of Berberis aristata and Silybum marianum standardized extracts versus only Berberis aristata in patients with type 2 diabetes. Clinical Pharmacology: Advances and Applications 5, 167-174.

Puoci, F., Iemma, F., Spizzirri, U. G., et al. (2011) Antioxidant activity of a Mediterranean food product: "fig syrup". Nutrients 3, 317-329.

Quispe, C., Petroll, K., Theoduloz, C., et al. (2014) Antioxidant effect and characterization of South American Prosopis pods syrup. Food Research International 56, 174-181.

Ramawat, K. G. \& Mérillon, J., eds. (2008) Bioactive Molecules and Medicinal Plants. Berlin: Springer-Verlag.

Rathee, S., Rathee, P., Rathee, D., et al. (2010) Phytochemical and pharmacological potential of Kair (Capparis decidua). International Journal of Phytomedicine 2, 10-17.

Ribeiro, A. B., Chisté, R. C., Freitas, M., et al. (2014) Psidium cattleianum fruit extracts are efficient in vitro scavengers of physiologically relevant reactive oxygen and nitrogen species. Food Chemistry 165, 140-148.

Roberfroid, M. B. (2007) Concepts and strategy of functional food science: the European perspective. American Journal of Clinical Nutrition 71, 1660-1664.

Romano, J. (2013) Therapeutic review: colchicine. Journal of Exotic Pet Medicine 22, 405-408.

Ross, S. (2000) Functional foods: the Food and Drug Administration perspective. American Journal of Clinical Nutrition 71, 1735-1738.

Rufino, M. S. M., Alves, R. E., Brito, E. S., et al. (2010) Bioactive compounds and antioxidant capacities of 18 non-traditional tropical fruits from Brazil. Food Chemistry 121, 996-1002.

Sarker S. D. \& Nahar, L., eds. (2012) Natural Products Isolation. New York: Humana Press, Springer.

Schippmann, U., Leaman, D. J. \& Cunningham, A. B. (2002) Impact of Cultivation and Gathering of Medicinal Plants on Biodiversity: Global Trends and Issues. FAO

Biodiversity and the Ecosystem Approach in Agriculture, Forestry and Fisheries. Satellite event on the occasion of the Ninth Regular Session of the Commission on Genetic Resources for Food and Agriculture. Inter-Departmental Working Group on Biological Diversity for Food and Agriculture. Rome: FAO.

Schulp, C. J. E., Thuiller, W. \& Verburg, P. H. (2014) Wild food in Europe: s synthesis of knowledge and data of terrestrial wild food as an ecosystem service. Ecological Economics 105, 292-305. 
Scicchitano, P., Cameli, M., Maiello, M., et al. (2014) Nutraceuticals and dyslipidaemia: beyond the common therapeutics. Journal of Functional Food 6, 11-32.

Sener, B. \& Orhan, L. (2005) Discovery of drug candidates from some Turkish plants and conservation of biodiversity. Pure and Applied Chemistry 77, 53-64.

Sengupta, G., Hazra, A., Kundu, A., et al. (2011) Comparison of Murraya koenigiiand Tribulus terrestris-based oral formulation versus tamsulosin in the treatment of benign prostatic hyperplasia in men aged $>50$ years: a double-blind, double-dummy, randomized controlled trial. Clinical Therapeutics 33, 1943-1952.

Sengupta, K., Krishnaraju, A. V., Vishal, A. A., et al. (2010) Comparative efficacy and tolerability of 5 -Loxin ${ }^{\circ}$ and Aflapin ${ }^{\circ}$ against osteoarthritis of the knee: a double blind, randomized, placebo controlled clinical study. International Journal of Medicinal Sciences 7, 366-377.

Shad, A. A., Ahmad, S., Ullah, R., et al. (2014) Phytochemical and biological activities of four wild medicinal plants. Scientific World Journal 2014, 1-7.

Sharma, B., Salunke, R., Balomajumder, C., et al. (2010) Anti-diabetic potential of alkaloid rich fraction from Capparis decidua on diabetic mice. Journal of Ethnopharmacology, 127, 457-462.

Shegokar, R. \& Müller, R. H. (2010) Nanocrystals: industrially feasible multifunctional formulation technology for poorly soluble actives. International Journal of Pharmaceutics 399, 129-139.

Sidor, A. \& Gramza-Michałowska, A. (2014) Advanced research on the antioxidant and health benefit of elderberry (Sambucus nigra) in food - a review. Journal of Functional Foods 18, 941-958.

Singh, A. P., Wilson, T., Kalk, A. J., et al. (2009) Isolation of specific cranberry flavonoids for biological activity assessment. Food Chemistry 116, 963-968.

Singh, J., \& Sinha, S. (2012) Classification, regulatory acts and applications of nutraceuticals for health. International Journal of Pharma and Bio Sciences 2, 177-187.

Spernath, A. \& Aserin, A. (2006) Microemulsions as carriers for drugs and nutraceuticals. Advances in Colloid and Interface Science 128-130, 47-64.

Stauss-Grabo, M., Atiyea, S., Warnke, A., et al. (2011) Observational study on the tolerability and safety of film-coated tablets containing ivy extract (Prospan ${ }^{\circ} \mathrm{Cough}$ Tablets) in the treatment of colds accompanied by coughing. Phytomedicine 18, 433-436.

Sticher, O. (2008) Natural product isolation. Natural Products Reports 25, 517-554.

Takachi, R., Inoue, M., Ishihara, J., et al. (2008) Fruit and vegetable intake and risk of total cancer and cardiovascular diseasee Japan public health center-based prospective study. American Journal of Epidemiology 167, 59-70.

Talbott, S. M., Talbott, J. A. \& Pugh, M. (2013) Effect of Magnolia officinalis and Phellodendron amurense (Relora ${ }^{\circledR}$ ) on cortisol and psychological mood state in moderately stressed subjects. Journal of the International Society of Sports Nutrition 10, 2-6.

Thomson, M., Al-Qattan, K. K., Al-Sawan, S. M., et al. (2002) The use of ginger (Zingiber officinale Rosc.) as a potential anti-inflammatory and antithrombotic agent. Prostaglandins, Leukotrienes and Essential Fatty Acids 67, 475-478.

Tijhuis, M. J., Jong, N., Pohjola, M. V., et al. (2012) State of the art in benefit-risk analysis: food and nutrition. Food and Chemical Toxicology 50, 5-25.

Trivedi, P. C., ed. (2009) Medicinal Plants: Utilisation and Conservation. Chaura Rasta: Aaviskar Publishers 
Tu, Y., Sun, W., Wan, Y., et al. (2013) Huangkui capsule, an extract from Abelmoschus manihot (L.) medic, ameliorates adriamycin-induced renal inflammation and glomerular injury via inhibiting $\mathrm{p} 38 \mathrm{MAPK}$ signaling pathway activity in rats. Journal of Ethnopharmacology 147, 311-320.

Vulić, J. J., Ćebović, T. N., Čanadanović-Brunet, J. M., et al. (2014) In vivo and in vitro antioxidant effects of beetroot pomace extracts. Journal of Functional Foods 6, 168-175.

Wagner, H. \& Jurcic, K. (2002) Immunological studies of Revitonil ${ }^{\bullet}$, a phytopharmaceutical containing Echinacea purpurea and Glycyrrhiza glabra root extract. Phytomedicine $\mathbf{9}$, 390-397.

Weathers, P. J. \& Towler, M. J. (2014) Changes in key constituents of clonally propagated Artemisia апииа L. during preparation of compressed leaf tablets for possible therapeutic use. Industrial Crops and Products 62, 173-178.

WHO (2003) Diet, Nutrition and the Prevention of Chronic Diseases. WHO Technical Report Series 916. Geneva: World Health Organization.

Wong, C. K., Tse, P. S., Wong, E. L. Y., et al. (2004) Immunomodulatory effects of Yun Zhi and Danshen capsules in health subjects - a randomized, double-blind, placebo-controlled, crossover study. International Immunopharmacology 4, 201-211.

Wootton-Beard, P. C. \& Ryan, L. (2011) A beetroot juice shot is a significant and convenient source of bioaccessible antioxidants. Journal of Functional Foods 3, 329-334.

Wrick, K. L. (2005) The impact of regulation on the business of nutraceuticals in the United States: yesterday, today, and tomorrow. In: C. M. Hasler, ed. Regulation of Functional Foods and Nutraceuticals: A Global Perspective. Ames: Wiley-Blackwell, pp 3-36.

Wu, P., Ma, G., Li, N., et al. (2015) Investigation of in vitro and in vivo antioxidant activities of flavonoids rich extract from the berries of Rhodomyrtus tomentosa (Ait.) Hassk. Food Chemistry 173, 194-202.

Xu, J., Seo, A. Y., Vorobyeva, D. A., et al. (2010) Beneficial effects of a Q-ter based nutritional mixture on functional performance, mitochondrial function, and oxidative stress in rats. PLoS One 5, 1-10.

Yakoot, M., Salem, A. \& Helmy, S. (2013) Effect of $\mathrm{Memo}^{\circ}$, a natural formula combination, on Mini-Mental State Examination scores in patients with mild cognitive impairment. Clinical Interventions in Aging 8, 975-981.

Yang, B., Jiang, Y., Shi, J., et al. (2011) Extraction and pharmacological properties of bioactive compounds from longan (Dimocarpus longan Lour.) fruit - a review. Food Research International 44, 1837-1842.

Yu, L., Jiang, B. P., Luo, D., et al. (2012) Bioactive components in the fruits of Ziziphus jujuba Mill. against the inflammatory irritant action of Euphorbia plants. Phytomedicine 19, 239-244.

Zeisel, S. H. (1999) Regulation of nutraceuticals. Science 285, 1853-1855.

Zhang, C. R., Dissanayake, A. A., Kevseroğlu, K., et al. (2015) Evaluation of coriander spice as a functional food by using in vitro bioassays. Food Chemistry 167, 24-29.

Zia-Ul-Haq, M., Ćavar, S., Qayum, M., et al. (2011) Compositional studies: antioxidant and antidiabetic activities of Capparis decidua (Forsk.) Edgew. International Journal of Molecular Sciences 12, 8846-8861. 